\title{
SOEP
}

SOEPpapers

SOEPpapers
on Multidisciplinary Panel Data Research
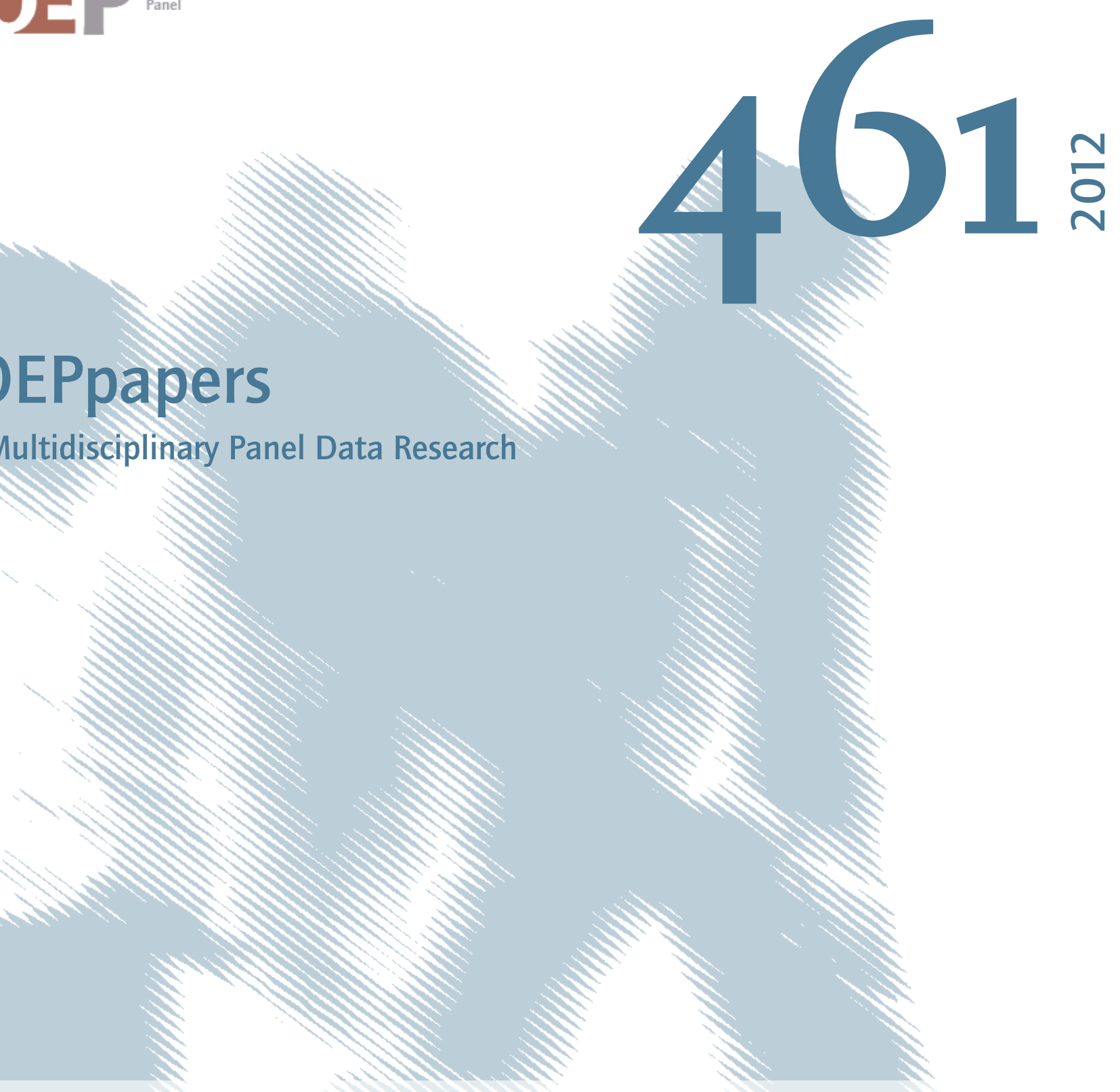

\section{A Satisfaction-Driven Poverty Indicator - A Bustle Around the Poverty Line}




\section{SOEPpapers on Multidisciplinary Panel Data Research}

at DIW Berlin

This series presents research findings based either directly on data from the German SocioEconomic Panel Study (SOEP) or using SOEP data as part of an internationally comparable data set (e.g. CNEF, ECHP, LIS, LWS, CHER/PACO). SOEP is a truly multidisciplinary household panel study covering a wide range of social and behavioral sciences: economics, sociology, psychology, survey methodology, econometrics and applied statistics, educational science, political science, public health, behavioral genetics, demography, geography, and sport science.

The decision to publish a submission in SOEPpapers is made by a board of editors chosen by the DIW Berlin to represent the wide range of disciplines covered by SOEP. There is no external referee process and papers are either accepted or rejected without revision. Papers appear in this series as works in progress and may also appear elsewhere. They often represent preliminary studies and are circulated to encourage discussion. Citation of such a paper should account for its provisional character. A revised version may be requested from the author directly.

Any opinions expressed in this series are those of the author(s) and not those of DIW Berlin. Research disseminated by DIW Berlin may include views on public policy issues, but the institute itself takes no institutional policy positions.

The SOEPpapers are available at

http://www.diw.de/soeppapers

\section{Editors:}

Jürgen Schupp (Sociology, Vice Dean DIW Graduate Center)

Gert G. Wagner (Social Sciences)

Conchita D'Ambrosio (Public Economics)

Denis Gerstorf (Psychology, DIW Research Professor)

Elke Holst (Gender Studies)

Frauke Kreuter (Survey Methodology, DIW Research Professor)

Martin Kroh (Political Science and Survey Methodology)

Frieder R. Lang (Psychology, DIW Research Professor)

Henning Lohmann (Sociology, DIW Research Professor)

Jörg-Peter Schräpler (Survey Methodology, DIW Research Professor)

Thomas Siedler (Empirical Economics)

C. Katharina Spieß (Empirical Economics and Educational Science)

ISSN: 1864-6689 (online)

German Socio-Economic Panel Study (SOEP)

DIW Berlin

Mohrenstrasse 58

10117 Berlin, Germany

Contact: Uta Rahmann | soeppapers@diw.de 


\title{
A Satisfaction-Driven Poverty Indicator - A Bustle Around the Poverty Line ${ }^{1}$
}

\author{
Andos Juhász (University of Tübingen)
}

This version: 30 . July 2012

\begin{abstract}
Poverty line definitions in use often lack a solid scientific foundation. This paper proposes to exploit data on income satisfaction to construct an evidence-based poverty line. The poverty line is identified by using its assumed unique property to explain income dissatisfaction best among all dichotomizations of income. To this end, several model settings are considered including linear and nonlinear approaches both exploiting panel information. Applying the method to data from the German Socio-Economic Panel yields a temporally stable poverty line similar to the definition provided by the Statistical Office of the European Commission. Using data from the European Community Household Panel, we present further evidence for satisfaction-based poverty lines across Europe and investigate their cross-country differences. The appropriateness of focusing on discrete poverty lines is also investigated.
\end{abstract}

JEL-Classification: D31, I32

Keywords: Household income, poverty line, income satisfaction

Correspondence:

Andos Juhász, Department of Economics, University of Tübingen, Mohlstr. 36, 72074 Tübingen, Germany, Fax: +49-7071-295013, andos.juhasz@uni-tuebingen.de

\footnotetext{
${ }^{1}$ I am grateful to Martin Biewen, Andrew Oswald, the participants of the THE Workshop at the University of Hohenheim and the Econometric Colloquium at the University of Tübingen for their comments and suggestions. All errors are my own. The data used in this paper (SOEP v26, 1994-2009 and ECHP, 1994-2001) were made available by the German Socio-Economic Panel Study (SOEP) at the German Institute for Economic Research (DIW), Berlin, and the Statistical Office of the European Commission.
} 


\section{Introduction}

When it comes to poverty line definitions, the literature offers a wide variety of concepts. There is extensive work on the question of how to define a poverty line according to underlying axioms and philosophical or conceptional perspectives. In an empirical paper, Ravallion (2010) analyzes national poverty lines of 95 countries reviewing their strongly varying national concepts. One of his important observations is that while relative, income-based poverty line definitions are typically chosen in developed countries, developing countries mostly use consumption based and absolute measures. ${ }^{2}$ The variety of national definitions mirrors different general concepts in poverty measurement such as the absolutistic 'basic needs concept' (related to physical survival) and the concept of 'relative deprivation' (related to social inclusion). ${ }^{3}$ It turns out that empirical poverty measures can be seen as combinations of the two main concepts. ${ }^{4}$ The classic example for an absolute poverty line definition is the international poverty line of $1.25 \$$ as proposed in Ravallion et al. (2008), updating the previous value of the World Bank (1990) of $1 \$$. A prominent example for a relative definition of poverty is the one used by the Statistical Office of the European Commission as $60 \%$ of the median income ${ }^{5}$. Such choices do not underrun a statistical optimization process in a rigid sense though. ${ }^{6}$

Moreover, a variety of approaches exists that are neither purely absolute nor relative. Prominent examples are called subjective poverty lines, see, e.g., Hagenaars, van Praag (1985). ${ }^{7}$ These poverty lines depend on how individuals perceive poverty in society. Two well-known concepts are the Leyden Poverty Line of Goedhart et al. (1977) and the Subjective Poverty Line as in Kapteyn et al. (1988). The theoretic background of these

\footnotetext{
${ }^{2}$ Focusing on consumption instead of monetary income helps to overcome the problem of measurability posed by agricultural production without explicit pricing.

${ }^{3}$ See Atkinson and Bourguignon (2001).

${ }^{4}$ This combination is also called 'weakly relative poverty', see Ravallion and Chen (2011).

${ }^{5}$ Throughout this paper we will refer to the equivalized nominal household income with the term 'income'.

${ }^{6}$ Krämer (1994) investigates the source of this definition in more detail. He accounts the first appearance of such a definition to Fuchs (1967): "I propose that we define as poor any family whose income is less than one-half of the median family income.[...] no special claim is made for the precise figure of one-half."

${ }^{7}$ Our poverty line definition belongs to this group.
} 
approaches is appealing in many aspects. The suggestion that poverty line definitions should be based on answers to survey questions is central. Nevertheless, both concepts rely on strong assumptions. A basic conceptual difference between the two approaches above and our definition of the Satisfaction-Driven Poverty Line (SDPL) given in this paper is the following one. While our SDPL approach is based on the hypothesis that "people are capable and willing to give meaningful answers to questions about their well-being" ${ }^{\prime}$, meaning that direct questions on individual well-being and utility do make good proxies for their own 'true' utility, the former two concepts implicitly make a much stronger assumption, namely that people are capable and willing to give meaningful answers to questions about life situations that they are not necessarily living in themselves. Although 'meaningfulness' can mean less than statistical unbiasedness, our belief is that while people are experts of their own lifes ${ }^{9}$, they are unlikely to be experts of other theoretical life situations.

To calculate the Satisfaction-Driven Poverty Line for Germany and twelve other European countries, we use a financial dissatisfaction indicator based on the variable 'satisfaction with household income' taken from the German Socio-Economic Panel (SOEP) and 'satisfaction with the household's financial situation' from the European Community Household Panel (ECHP). Controlling for a function of equivalized household income and other sociodemographic variables, we add an a-priori unspecified binary variable of income as an independent variable. Assuming, the true poverty $\operatorname{line}^{10}$ has the unique property of best explaining income dissatisfaction, we identify the best choice of dichotomization in this sense and call it SDPL. Empirically, the poverty line is given as the maximizer of the goodness-of-fit of the underlying regression.

It is important to point out that this approach is not restricted to an absolute or relative definition of the poverty line. ${ }^{11}$ A-priori, it may well be constant over time or a constant percentage point of the median or have any other behavior. Furthermore, our approach does

\footnotetext{
${ }^{8}$ See Frey and Stutzer (2002).

${ }^{9}$ This view is supported by actual research. For phychological justification see Diener et al. (1993) and Kahneman (1999) or Blanchflower and Oswald (2008) and Steptoe and Wardle (2005) for health related arguments. For a more general view see Ferrer-i-Carbonell (2011).

${ }^{10}$ The question of existence will also be investigated.

${ }^{11}$ Why such choices may lead to too restrictive measures, see e.g. Ravallion (2010) p.17.
} 
not rely on restricting assumptions concerning the explicit functional relationship between income and income utility. It is assumed though that reported income dissatisfaction is classified correctly, that the same classification translates to true (theoretical) monetary disutility and that the underlying disutility classification is best explained by true poverty. The reduction to monetary disutility arises naturally as our space of poverty classifications is itself restricted to income.

The aim of our paper is to reveal a sofar unexploited relationship between income satisfaction and income in order to construct a poverty line. Furthermore we show that this relationship contains a characterization of the widely-used definition of the poverty line by the Statistical Office of the European Commission at $60 \%$ of the median based on a statistically founded optimization criterion for Germany. Additionally, we show that our approach provides evidence for a sharp, discrete poverty line, rather than a fuzzy one ${ }^{12}$. For other European countries we show that the above relationship is not only a Germany-specific phenomenon, but it also exists in other European countries. There is evidence though that the country-specific optima deviate from the 60\%-definition to some extent elsewhere. Nevertheless, results show that differences among countries in their estimated poverty lines can be explained quite well by the heterogeneity of macroeconomic characteristics.

The rest of our paper is organized as follows. In Section 2 we introduce both data sets and motivate the choice of variables. Section 3 explains our methodologies in detail. Section 4 presents the empirical results using data from the SOEP for Germany and Section 5 the ECHP for international poverty lines. Section 6 concludes.

\section{Data and Variable Selection}

The German Socio-Economic Panel (SOEP) is provided by the German Institute for Economic Research (DIW) in Berlin. ${ }^{13}$ The SOEP is a representative yearly panel study of private households in Germany. In 2009 almost 25,000 individuals living in about 11,000 households

\footnotetext{
${ }^{12} \mathrm{An}$ example for a class of such poverty lines can be found in Belhadj (2011)

${ }^{13}$ For more details see Haisken-DeNew and Frick (2005) or Wagner et al. (2007).
} 
were interviewed. ${ }^{14}$ The survey contains detailed information on a wide variety of personal and household level characteristics covering social, demographic, economic variables and variables of subjective well-being. The European Community Household Panel (ECHP) on the other hand is a representative panel survey provided by the Statistical Office of the European Commission, Eurostat. For a period of eight years, 1994-2001, households were interviewed to collect information on their income and living conditions on personal and household level on a yearly basis. The interviews cover a wide range of topics on living conditions such as income information, financial and housing situation, working life, social relations, health and biographical information. ${ }^{15}$ In the first wave in 1994, a sample of around 60,500 households with around 130,000 adults were interviewed in twelve European Countries. Those countries were Germany, Denmark, the Netherlands, Belgium, Luxembourg, France, United Kingdom, Ireland, Italy, Greece, Spain and Portugal. Austria and Finland joined the project in 1995 and 1996 respectively and Sweden in the year 1997, based on the Swedish Living Conditions Survey. After 1996, German data was derived from the SOEP, data for Luxembourg from the Luxembourg Income Study and data for the United Kingdom from the British Household Panel Survey. Due to missing ECHP satisfaction variable we cannot make use of the data for Sweden. Also data for Germany, Luxembourg and the United Kingdom lack a satisfaction variable with ECHP-consistent definition when using national databases. Data for France cannot be used as household income is only available as gross income. With these limitations the full set of data with respondents of age $17+$ with non-proxy interviews and available satisfaction and income data is used and we consider the following countries.

- Denmark, the Netherlands, Belgium, Ireland, Italy, Greece, Spain and Portugal (19942001),

- Austria (1995-2001), Finland (1996-2001),

- Germany, Luxembourg and the United Kingdom (1994-1996).

\footnotetext{
${ }^{14}$ We did not use households with missing income information or incomplete age structure, but besides that we made no other restrictions.

${ }^{15}$ For more on the ECHP, see http://epp.eurostat.ec.europa.eu/portal/page/portal/microdata/echp.
} 


\section{Variable selection}

In the field of happiness economics researchers frequently use direct questionnaire-based overall life satisfaction to proxy the 'true' overall welfare. At first glance it is hard to believe that happiness or unhappiness can be put in numbers in a proper and scientifically useable way by regular respondents. One may think that it is an impossible task to express the notion of happiness quantitatively, or one might think that - if it was possible conceptually - it is unlikely to work if non-experts are asked with only a couple of seconds to decide. However, research on the subject tells a quite different story. As summarized by Ferrer-i-Carbonell (2011), there seems to be a strong statistical relationship between the proxy and true satisfaction. The connection can be revealed by using objective psychological measures of happiness, based e.g. on facial expressions or body language as investigated by Sandvik et al. (1993) and Kahneman (1999) or objectively measurable brain activity as reported in Urry et al. (2004). Furthermore, researchers found that there is evidence for the existence of a commonly shared context of happiness, so that the comparison of answers of different individuals is generally possible. ${ }^{16}$ When putting this picture together, it seems to be that such "... happiness measures are consistent, valid, and reliable. In sum, it appears that human happiness is a real phenomenon that we can measure." 17

\section{Income Satisfaction as dependent variable}

When it comes to subjective monetary poverty line definitions, personal utility of income or income-driven welfare is the center of interest. The limitation to this very aspect of welfare makes sense as the one-dimensional monetary approach is limited on its own, likely to be driven less substantially by information arising from income-complementary welfare aspects. While it is well-known that "money alone does not make happy" 18 , shown by a weak - but significant - relationship between income and life satisfaction, we may expect much more in this regards when using income satisfaction instead. Indeed, the SOEP shows only a weak correlation of around 0.15 between income and life satisfaction, while the correlation is around

\footnotetext{
${ }^{16}$ See, for example, Van Praag (1991).

${ }^{17}$ See Frank (2005).

${ }^{18}$ See e.g. Ferrer-i-Carbonell and Frijters (2004).
} 
0.35 when using income satisfaction instead. On the other hand, it is important to see that while satisfaction with income has a rather specific formulation, responses are correlated with the ones about life as a whole to an extent of around 0.5. This gives rise to the assumption that income satisfaction is influenced by non-pecuniary life circumstances. Consequently, our particular interest lies in reported income satisfaction, the answer to the question "How satisfied are you today with your household income?" on a scale from 0 to 10 . The scale in use here is called a bipolar 11-point-scale ${ }^{19}$ with the numbers 0-2 explicitly tagged 'totally unhappy' and 9-10 tagged 'totally happy'. ${ }^{20}$ Such a scale has advantages over other possible scales, see Abrams (1973) or the more recent Kroh (2005). A typical distribution of the answers to this question is given in Figure 1. The response rate of over $90 \%$ shows the willingness of the interviewees to answer to this question. ${ }^{21}$ The fact that the scale is used in entirety without dominating corner solutions, suggests that the respondents are also willing to maximize the submitted information. 22

- Figure 1 around here -

As regards the ECHP, the data set offers satisfaction with the household's financial situation for the dependent variable. This is slightly different from the variable available from the SOEP. To obtain a comparable relationship to actual income it is more important to account for the overall financial situation. ${ }^{23}$ We will go into detail on the additional controls used to handle this issue at the end of this subsection. Another important difference between the two satisfaction variables is that while the SOEP variable is given on an 11-point-scale, the ECHP variable is given on a 6-point scale. This may be a limitation leading to less detailed results.

\footnotetext{
${ }^{19}$ For more on the origins of the scale see, e.g., Wagner (2007).

${ }^{20}$ As opposed to a bipolar scale a unipolar scale would run from 'totally not happy' to 'totally happy', that is from the total absence to the total presence of the same issue. This can be seen as restrictive if the lack of happiness is not necessarily interpreted as unhappiness.

${ }^{21}$ For our analyzes we make use of the unrestricted sample including every respondent to the income satisfaction question with known household income.

${ }^{22}$ The opposite would be the case if people just used 0 or 10 to communicate their being unhappy or being happy respectively, as we would not be able to differentiate between answers within the two groups.

${ }^{23}$ This is less important when using panel data as slowly changing characteristics such as wealth can be netted out.
} 


\section{Income as independent variable}

A central point is to explain income-driven welfare based on household income. Using the household income instead of the individual income is a very common approach. Households are well-defined economic units that usually share their income sources and exhibit economyof-scale effects. Both have to be accounted for when calculating the households' individual incomes. The most common approach is to apply equivalence scales ${ }^{24}$ to account for the intra-household redistribution of income. Once we have accounted for this redistribution, a third degree polynomial ${ }^{25}$ of the resulting equivalized personal income is used to explain the income-driven satisfaction.

\section{Direct effects on income perception}

To uncover the direct relationship between income and income satisfaction, we control for other factors that may influence reported income satisfaction. Firstly, the overall financial situation is not captured by income, but may well have an important effect on answers, e.g. as high wealth makes a person less dependent on income. ${ }^{26}$ We take two measures to control for this. As we do not have yearly data on financial wealth ${ }^{27}$, we use house ownership as proxy. Furthermore, fixed effects approaches will net out such effects, assumed they are time constant. Secondly, we notice that relative income perception may be a part of the relationship between income and income satisfaction. To model such effects though, relevant social groups that the individual relates to and potentially compares himself with need to be identified. ${ }^{28}$ Generally, it is not obvious which group a person relates to (colleagues, friends, neighbors, family members, etc.). However, we control for a very general way of relative income effects by including the unspecified poverty indicator in our regressions, which will also pick up relative income concerns as shown in section 5 (by the significance of the Gini coefficents in the country panel).

\footnotetext{
${ }^{24}$ We use the commonly used scale, called new OECD scale, assigning the weight 1 to the household head, 0.5 for every other adult in the household and 0.3 for every child, but we also check for the robustness of this choice by using the Luxembourg scale with no qualitative difference in the results.

${ }^{25}$ Robustness test were performed by using only a second degree polynomial and by using logarithmic income instead of a polynomial. This led to very similar results.

${ }^{26}$ For more details see e.g. Headey and Wooden (2004).

${ }^{27}$ The SOEP only contains detailed wealth related data for two selected years.

${ }^{28}$ For more details see D'Ambrosio and Frick (2007), Clark and Senik (2010), Clark and Oswald (1996) or Luttmer (2005) among others.
} 
A third point that can be efficiently controlled for is the source of income. It may be important whether people work for their income on their own or whether they receive income from the state, e.g., in form of social welfare. Besides the direct monetary effects, strong non-monetary effects are expected. The latter effect may also be interpreted as undervaluation of the income, e.g., from social welfare. For more details concerning different effects of unemployment benefits see Winkelmann and Winkelmann (1998). Here we control for the number of months in the previous year the household received social welfare, unemployment benefits and unemployment assistance. Furthermore we control for part-time employment, retirement status, unemployment and being out of labor force. A further and last point is income adaptation that generally plays a role for subjective income valuation. ${ }^{29}$ In this regards though, we refer to DiTella and MacCulloch (2008), who find that income adaptation is likely to be less pronounced for poverty-relevant subgroups. Nevertheless, we control for the number of month, the household received social welfare as mentioned above. This also controls for potential adaptation effects for the recipients. Furthermore, long term adaptation effects are netted when using fixed effects.

\section{Indirect effects on income perception}

Another set of controls has a more indirect impact on income perception. It is rather connected to complementary aspects of overall welfare as opposed to income-driven welfare. It is likely that impacts on aspects of life other than income may indirectly influence the perception of income, leading to an alteration of its perception. For example, people may not really refer to their income only if asked, but they may also be influenced and biased by other circumstances. Four subgroups that we see as relevant in this regards are attitude and personality, major life events, health and social network. Attitude and personality summarize the individual specific view of the world. Attitude typically cannot be measured directly, but assuming its mainly constant character it can be accounted for when panel data is available. As numerous other aspects of individual personality traits can be at least indirectly controlled for, we account for this group with the variables gender, age and education, where we use a

\footnotetext{
${ }^{29}$ For an early work on adaptation see Brickman et al. (1978) or for an ongoing discussion Ferrer-i-Carbonell and Van Praag (2009).
} 
dummy of high school degree and a dummy for apprenticeship or German Abitur as highest degree for education. Additionally, we control for being in education at the time of the interview.

Major life events are positive or negative shocks which may also bias the answers on income satisfaction. For example, if the beloved dog of the family dies just the day before the interview, the interviewee's answer to the question may be downward biased due to his bad mood. ${ }^{30}$ As controls we use a dummy for a child born in the past six months, newly married in the last twelve months, divorced in the last six months, newly disabled in the last twelve months. Furthermore we control for deaths in the household in the last twelve months and children under fourteen that left the household in the last six months. In addition, we control for events in the household's near future. This clearly only makes sense for events that people can anticipate and that can be associated with psychological effects. Our choice here is to take divorce in the next twelve months and marriage in the next six months. Another category is health. Here we control for the number of days spent ill in the last year and the disability grade. The last category is social network. Controls belonging to this set relate to information about other individuals that the individual in question is aware of. While it is hard to characterize the influence of the social network in general, we may say that if a person is living with a social network that is in harmony with his personal attributes, he should feel happier than someone, who's social network is very different from the desired one. This can be people who desire more friends or a bigger family. To control for the social network, we control for marital status including being separated and children including age structure. We control for children between zero and three years, four to eleven years and twelve to seventeen years in the household with dummy variables. Controlling for other effects requires knowledge about the relevant social structure and the perception of it, both of which are likely to vary with the individual and are beyond the scope of our work. However, also here, fixed effects will net out such effects to a fair extent.

As already pointed out, there are some differences in the choice of controls when using the ECHP. The differences result from the different data sets on the one hand and from the

\footnotetext{
${ }^{30}$ For more on the direct effects of such events on general life satisfaction see Mentzakis (2011).
} 
fact that the financial situation has to be accounted for more explicitly on the other. To additionally control for the latter, we use the quartile membership of household capital income and rental income, debts and loan dummies and house ownership. Furthermore we control for unemployment, unemployment frequency since 1989, highest education dummies, disability in two stages of severity, new deaths, new births, marital status, employment, retirement, positive and negative subjective income shock since last year and EU and non-EU foreigner dummies. Finally, we control for the quartile position in the distribution of doctor visits as an objective control for health.

\section{Methodology}

\subsection{Motivation}

There is a wide range of econometric approaches used in recent literature about self-reported satisfaction. Much has changed due to the availability of new methods, advance in computation and due to new insights into the nature of the satisfaction variable. Typically, in the field of psychology simple cross sectional regression approaches were used to explain the role of different influence factors on self-reported satisfaction. Such approaches clearly rely on the cardinality assumption of the dependent variable. ${ }^{31}$ If we rather want to assume ordinality only, nonlinear models like ordered logit models are the methods of choice. Such models have been widely used in economic literature, see e.g. Blanchflower and Oswald (2004). A drawback of cross-sectional approaches is that they cannot account for time constant individual heterogeneity. When assuming ordinality, the fixed effect logit model in Chamberlain (1980) can be used to overcome this problem. For an application see Winkelmann and Winkelmann (1998). As the latter model needs a binary dependent variable, a dichotomization of the satisfaction variable has to be used, generally leading to a loss of information.

According to Huppert and Whittington (2003), an additional issue arises if self-reported satisfaction is used. They state that the determinants of low satisfaction (dissatisfaction)

\footnotetext{
${ }^{31}$ For examples see e.g. Diener et al. (1999).
} 
and high satisfaction are different. For their analysis they use two distinct satisfaction scales: one explicitly describing well-being, the other one describing the presence and absence of symptoms for mental and physical health related problems. As standard ordered logit based models are structurally limited through their single crossing property ${ }^{32}$, they are likely to be too restrictive to capture heterogenous impacts according to the above findings properly. Based on the cross-sectional generalized ordered probit model in Terza (1985), Boes und Winkelmann (2010) introduce a panel based extension with correlated random effects, assuming ordinality, while accounting for scale heterogeneity and unobserved individual heterogeneity.

An aim of our study is to reveal a relationship between income satisfaction and income, implicitly defining an income poverty line. We start by defining the poverty line in a strict binary sense based on a dummy variable of income. Starting from a relationship given by a third degree polynomial in income and controls mentioned in the last section, we introduce an additional explanatory variable in form of the above mentioned dummy without defining its exact position. We have already motivated the use of satisfaction with income instead of general life satisfaction for the estimation of the satisfaction-driven poverty line (SDPL) in the last section. As we are only interested in the relationship between poverty and clear income dissatisfaction, we use a dichotomization of income satisfaction instead of income satisfaction itself. The resulting binary variable has the value 0 for all people that are dissatisfied with their incomes and 1 for all others. As the SOEP's income satisfaction question explicitly labels the answers 0,1 and 2 as 'totally unhappy', we see our choice to take the cutoff point 2 as well-founded. ${ }^{33}$ In the case of the financial satisfaction variable of the ECHP, choice is much more limited. Here only the value of 1 is explicitly labeled as 'not satisfied at all', making other choices speculative. We therefore chose 1 as our cutoff point. Using the binary dependent variable defined above and a simple regression yield a linear probability model in which the marginal effect of the dummy variable for income has the straightforward interpretation of a change in probability to not being totally unhappy with income. Such a jump in probability can then be interpreted as the location of leaving poverty as argued in the first section. We define the best dummy variable to explain the relationship between income and income satisfaction as the satisfaction- driven poverty indicator.

\footnotetext{
${ }^{32}$ See Maddala (1983) for more details.

${ }^{33}$ Additionally, it turns out that taking 1 or 3 do not make a qualitative difference.
} 
The dichotomization of income satisfaction has the additional advantage of circumventing the scale heterogeneity problem mentioned above. ${ }^{34}$ Otherwise we would need to deal with generally different impacts of income on different levels of satisfaction to avoid mixture-driven outcomes. In addition to this, there are some computational reasons for us to prefer models based on the cardinality assumption. To perform a detailed grid search on the dummy variable, we need to repeat the model estimations a large number of times. While maximum likelihood methods generally take much longer time to calculate, a number of them also suffer from numerical drawbacks due to local extrema and saddle points with suboptimal solutions that are hard to identify. This problem is especially pronounced with high numbers of repetitions leading potentially to suboptimal grid maxima. Fortunately, empirical research frequently comes to the conclusion that while the ordinality assumption is the right choice in theory, there are no practical differences to the results when compared to cardinality-based methods. See Boes and Winkelmann (2010) for such a conclusion. Following these arguments we use the cardinality assumption in our research leading to linear models when performing grid search. ${ }^{35}$ As controlling for individual heterogeneity is also empirically important in general ${ }^{36}$, we extend our analysis to the use of fixed effects panel models. Additionally, we introduce a more flexible approach based on nonlinear least squares both in the cross-sectional and the fixed effects panel setting.

\subsection{The Grid Search Approach}

The idea of the following approaches is to estimate the poverty line as the income value that maximizes the goodness-of-fit of a model explaining income satisfaction by the variables defined above. Assume the following underlying relationship

$$
s_{i t}=\beta_{0}+\mathbf{x}_{i t}^{\prime} \beta+g\left(\pi, \iota_{i t}\right) \gamma(\pi)+u_{i t}, \quad i \in\{1, \ldots, N\}, t \in\{1, \ldots, T\},
$$

with $i$ as cross sectional and $t$ as time index respectively, $\beta_{0}$ as intercept, $\beta:=\left(\beta_{1}, \beta_{2}, \ldots, \beta_{K}\right)^{\prime}$ as $K \times 1$ real vector of coefficients, $\mathbf{x}_{i t}:=\left(x_{i t 1}, x_{i t 2}, \ldots, x_{i t K}\right)^{\prime}$ as independent variables, $s_{i t}$

\footnotetext{
${ }^{34}$ See Boes and Winkelmann (2010).

${ }^{35}$ Nevertheless, for robustness checks we use a cross sectional logit model for comparison, yielding very similar results.

${ }^{36}$ See, for example, Ferrer-i-Carbonell and Frijters (2004).
} 
as the dependent variable income satisfaction, $\iota_{i t}$ as the income of person $i$ at time $t$ and $u_{i t}$ as an additive error term for all $i$ and $t .{ }^{37}$ Additionally, let $g(\pi, a):=\mathbf{1}_{\{a>\pi\}}(a)$ be a dichotomous function and $\gamma(\pi)$ a real valued coefficient that generally depends on the value of $\pi$, where $\pi$ is the point of income dichotomization.

In the special case of $T=1$ we have

$$
s_{i}=\beta_{0}+\mathbf{x}_{i}^{\prime} \beta+g\left(\pi, \iota_{i}\right) \gamma(\pi)+u_{i}
$$

which can be estimated by ordinary least squares given the usual regularity conditions for any fixed, positive $\pi$ yielding the usual

$$
R^{2}(\pi)=\max _{\beta, \gamma(\pi)} \sum_{i \in N}\left(\mathbf{x}_{i}^{\prime} \beta+g\left(\pi, \iota_{i}\right) \gamma(\pi)-\bar{s}\right)^{2} \cdot\left(\sum_{i \in N}\left(s_{i}-\bar{s}\right)^{2}\right)^{-1}
$$

as solution of the maximization problem with $R^{2}(\pi)$ as the standard goodness-of-fit measure and $\bar{s}$ as the arithmetic mean of the $s_{i}$.

It follows that for a finite grid $G \subset \mathbb{R}, \# G<\infty$, we can extend our maximization problem and get

$$
R_{G}^{2}:=\max _{\pi \in G} R^{2}(\pi)=\max _{\beta, \gamma, \pi} \sum_{i \in N}\left(\mathbf{x}_{i}^{\prime} \beta+g\left(\pi, \iota_{i}\right) \gamma(\pi)-\bar{s}\right)^{2} \cdot\left(\sum_{i \in N}\left(s_{i}-\bar{s}\right)^{2}\right)^{-1}
$$

yielding the SDPL

$$
\hat{\pi}:=\operatorname{argmax}_{\pi \in G} R^{2}(\pi),
$$

i.e. the poverty line that makes the relationship between income satisfaction and poverty status as strong as possible.

Consider now another configuration that makes use of a possible panel structure of the data. Given $T>1$ and putting $u_{i t}:=v_{i}+\epsilon_{i t}$ as the sum of individual unobservable heterogeneity $v_{i}$ and an idiosyncratic error term $\epsilon_{i t}$ in (1) we obtain

$$
s_{i t}=\beta_{0}+\mathbf{x}_{i t}^{\prime} \beta+g\left(\pi, \iota_{i t}\right) \gamma(\pi)+v_{i}+\epsilon_{i t}, \quad i \in\{1, \ldots, N\}, t \in\{1, \ldots, T\} .
$$

\footnotetext{
${ }^{37}$ We suppress the $i$ in $T_{i}$ allowing for unbalanced panels for notational simplicity.
} 
As the above strategy remains basically unchanged for either of the usual panel data models using least squares estimation, we keep the exposition brief. It is important to point out that $g\left(\pi, \iota_{i t}\right)$ is typically time variant, so time demeaning or usual differentiating strategies do not endanger the identifiability of $\hat{\pi}$. Furthermore, the goodness-of-fit measure we use is the $R^{2}$ based on the time demeaned least squares regression, also called 'within' $R^{2}{ }^{38}$

While the above approach is conceptually simple, it has two main drawbacks. The first theoretical - one is that the solution generally depends on the choice of $G$ and it is unlikely to equal the global solution on $\mathbb{R}$. The second - practical - one is that it may require a fair amount of computational time to calculate $\# G$ regressions, especially if panel data models are involved in the calculation. Both of these problems can be solved as shown in the next subsection.

\subsection{The Nonlinear Least Squares Approach}

To put the grid search in a more familiar econometric setting consider the following cross sectional relationship

$$
s_{i}=f\left(\tilde{\mathbf{x}}_{i}, \tilde{\beta}\right)+u_{i}
$$

with $f$ as a not necessarily linear function of the independent variables $\tilde{\mathbf{x}}_{i}$, a vector of coefficients $\tilde{\beta}$ and an additive error term $u_{i}$. In our case let

$$
f\left(\tilde{\mathbf{x}}_{i}, \tilde{\beta}\right)=\beta_{0}+\mathbf{x}_{i t}^{\prime} \beta+\mathbf{1}_{\{a>\pi\}}(a) \cdot \gamma(\pi)
$$

To estimate the coefficient vector $\tilde{\beta}=(\beta, \gamma, \pi)$, a nonlinear least squares (NLS) approach can be carried out given sufficient regularity conditions and conditions of identification as described in Wooldridge (2002), Chapter 12. While most of the conditions are rather unproblematic for empirical application, in our special case $f$ violates the necessary condition of being continuous on the parameter space. This is why (7) given (8) cannot be estimated directly.

To overcome this problem we choose a function that is very similar to the indicator function but is sufficiently smooth for a consistent NLS estimation. It can be seen easily that the

\footnotetext{
${ }^{38}$ Also compare equation (14) below.
} 
cumulative distribution function (CDF) of the logistic distribution

$$
\Lambda(x, \alpha, \beta):=\frac{1}{1+e^{-(x-\alpha) / \beta}}
$$

is a smooth function with location parameter $\alpha$ and scale parameter $\beta$. Furthermore it can be shown that for all $\alpha \in \mathbb{R}$

$$
\Lambda(x, \alpha, \beta) \underset{\beta \searrow 0}{\longrightarrow} \mathbf{1}_{\{x>\alpha\}}(x)
$$

pointwise, making the choice especially attractive. Nevertheless, there are other choices that approximate the indicator function even better. Note that $\Lambda(x, \alpha, \beta) \neq 1_{\{x>\alpha\}}(x) \forall x \in \mathbb{R}$ given any $\beta>0$ as the CDF of the logistic distribution never equals zero or one for finite $x$. This problem is not present if one takes

$$
\Pi(x, \alpha, \beta):= \begin{cases}0 & \text { if } x<\alpha \\ 10 \cdot\left(\frac{x-\alpha}{\beta}\right)^{3}-15 \cdot\left(\frac{x-\alpha}{\beta}\right)^{4}+6 \cdot\left(\frac{x-\alpha}{\beta}\right)^{5} & \text { if } \alpha \leq x \leq \alpha+\beta \\ 1 & \text { if } x>\alpha+\beta,\end{cases}
$$

constructed to be sufficiently smooth in $\alpha$ and $\alpha+\beta$ and again

$$
\Pi(x, \alpha, \beta) \underset{\beta \searrow 0}{\longrightarrow} \mathbf{1}_{\{x>\alpha\}}(x) .
$$

The advantage of this function is that it equals the indicator function on the complement of its middle section for all choices of $\beta>0$. Besides that, in the next section we can use both of the above approaches for robustness checks. For a clearer comparison of $\Lambda, \Pi$ and the indicator function see Figure 2 for an illustrative example.

- Figure 2 around here -

When inserting either (9) or (10) into (8) the model parameters can be estimated by nonlinear least squares. Besides that, we also gain a more flexible model with the additional parameter $\beta$. While in the case of $\Pi$ we have a direct interpretation of $\beta$ as the length of the transition region between 0 and 1 , a similar interpretation applies in the case of $\Lambda$ if we define the length of the transition region as the one between $\Lambda^{-1}(\epsilon)$ and $\Lambda^{-1}(1-\epsilon)$, with $\epsilon=0.05$ for example, as the values zero and one are never achieved. This yields for $\alpha=0$

$$
\Lambda^{-1}(0.95,0, \beta)-\Lambda^{-1}(0.05,0, \beta)=2 \cdot \Lambda^{-1}(0.05,0, \beta) \approx 5.889 \cdot \beta
$$


without loss of generality. If we take a look at Figure 2 we may recall the 3 elements of the region of interest explicitly. The height of the jump that we may also interpret as the marginal probability effect of the state change of being poor by SDPL definition to not being poor by SDPL definition is represented by the vertical section of the dotted line and is of the magnitude of around $17 \%$. It means that given a ceteris paribus state change to being not poor comes along with a $17 \%$ higher probability, namely around $92 \%$ probability, of not being dissatisfied with income. The second element is the jump distance or the length of the poverty transition region (PTR). While it is zero in the indicator case, it is around 80 Euros in the logistic and polynomial cases, meaning that in this case changing one's state from poor to not poor is not a discrete phenomenon. The third element is the location of the jump. In the logistic and polynomial cases it may be defined as the end of the jump for example and in the indicator case it is more clearly the point of dichotomization. The number here is somewhat around 400 Euros, the estimate for the SDPL for Germany in 1985.

\subsection{The Fixed Effects Nonlinear Least Squares Approach}

Given

$$
s_{i t}=f\left(\tilde{x}_{i t}, \tilde{\beta}\right)+v_{i}+\epsilon_{i t}
$$

time demeaning leads to

$$
\ddot{s}_{i t}=\ddot{f}\left(\tilde{x}_{i t}, \tilde{\beta}\right)+\ddot{\epsilon}_{i t}
$$

with $\quad \ddot{s}_{i t}:=s_{i t}-1 / J \cdot \sum_{j=1}^{J} s_{i t-j+1}, \quad \ddot{f}_{i t}:=f_{i t}-1 / J \cdot \sum_{j=1}^{J} f_{i t-j+1}$ and $\ddot{\epsilon}_{i t}:=\epsilon_{i t}-1 / J \cdot \sum_{j=1}^{J} \epsilon_{i t-j+1}$ respectively for time horizon $J$.

While there is no simplified expression for $\ddot{f}$ in general, estimation is still possible if $f$ follows necessary regularity conditions emerging directly from the cross sectional NLS case. Minimization of the empirical counterpart of $\ddot{\epsilon}_{i t}$ is equivalent to minimization of the population variable $E\left(\epsilon_{i t}^{2}\right)$ in (12) because

$$
E\left(\ddot{\epsilon}_{i t}^{2}\right)=E\left(\epsilon_{i t}^{2}\right) \cdot(1-1 / J)
$$

for all fixed $J .^{39}$

\footnotetext{
${ }^{39}$ See Wooldridge (2002), equation (10.51).
} 
We call this approach fixed effects nonlinear least squares approach (FENLS) throughout the rest of this paper. Using this model is particularly desirable as it both accounts for individual heterogeneity and posses a higher degree of freedom to adjust to the problem at hand, allowing to test for additional hypotheses.

\section{Empirical Results}

\subsection{SDPLs based on the SOEP}

After applying the grid search method as described in Section 3 to the SOEP, we obtain results as shown in the Figures $3 a-d$ and $4 a-d .{ }^{40}$ Each plot can be interpreted as follows. The value zero is the baseline R-squared of the underlying regression, without the poverty dummy. The additional gain in R-squared is given by the solid line with the poverty line set for the value as depicted on the x-axis. The highest gain is normalized to one. The grid applied to the search is between 150 and 4000 Euros in nominal value in 5 Euro steps. The first four figures show grid search results based on the linear probability model for the years 1985, 1995, 2005 and 2009. The last four figures show grid search results based on the fixed effects model of 3 consecutive years. Results here are labeled with the middle year as 1986, 1996, 2006 and 2008. The dotted vertical lines show $60 \%$ of the median. Despite the time span of 25 years, results are very robust. Dichotomizations at around $60 \%$ of the median deliver the highest explanatory power of the variable with pronounced unimodal shapes from $1994 .{ }^{41}$ Both cross sectional and panel approaches yield very similar results.

- Figures 3a-d and 4a-d around here -

Table 2 shows the regression results at the maxima based on data between 2007 and 2009 . Additionally, we present results based on data of one decade earlier for comparison in Table 1. Columns marked by (1) show the results based on the linear probability model, (2) based on the fixed effects model with full set of controls, (3) shows fixed effects without the income

\footnotetext{
${ }^{40}$ The results shown are also qualitatively representative for the years not depicted.

${ }^{41}$ Two consecutive years shortly after the German unification are generally the only bimodal exceptions.
} 
dummy variable and (4) shows results for the case, where no additional controls are used besides income.

- Table 1 and Table 2 around here -

While for (1) the full set of controls is used as described in Section 2, we drop some of them for the fixed effects models. We cannot make use of the time invariant regressors gender and East German origin, and age is dropped as year dummies are employed in the fixed effects regressions. Furthermore we excluded variables with very weak time variation such as house ownership, university degree and Abitur/vocational training. Additionally, we dropped the controls for major life events as their impacts were already erratic in the cross sectional case, and as they were highly insignificant in the fixed effects model.

Despite the differences in the models, the coefficients of the third degree polynomial of income have the same magnitude. In the relevant income segment the marginal effect of income is positive and falling in income, in line with the general assumption that the marginal utility of income is a convex function. The additional dummy variable of income is always positive and highly significant ranging between $8 \%$ and $9 \%$ for 1998 and between $9 \%$ and $13.4 \%$ for 2008 , always smaller in the fixed effects model. When plotting the probability effects arising from the income variables only, Figure 5 shows strong differences between the dummy-included and dummy-excluded models. Exclusion leads to local underestimation of the effect of income of up to $5 \%$ around the jump. When comparing (2) and (3) we see for both years that the inclusion of the dummy variable is not only reasonable in terms of the high significance of the variable, but also raises the fit of the regressions from 0.0313 to 0.0395 in 1998 and from 0.0341 to 0.0390 in 2008 by a considerable amount. When we take a look at the constants of the regressions, they range between $68.5 \%$ and $92.5 \%$ for 1998 and between $76 \%$ and $93 \%$ for 2008. Naturally, these baseline probabilities of not being dissatisfied with income cannot be compared directly as they are valid for different reference individuals. For example, the effect of age ranges between 0 and $-10 \%$ with a minimum at around 42 years of age in 1998 and around 50 for 2008 in the linear probability model, while age is only included squared in the fixed effects regressions and is never significant. 
While the coefficient of married is high and significant with $4.75 \%$ and $2.2 \%$ respectively, its effect vanishes when using the fixed effects model. The effect of separated varies strongly, but it is below zero as to be expected if significant in 1998. In the FE cases estimates of the latter two variables may be weak due to a weak time variation in the panel. The gender coefficient suggests a somewhat higher probability of not being dissatisfied with income for females, but the evidence is not strong. The East German dummy is significant in 1998, but not any more in 2008, indicating a vanishing heterogeneity in the German population. Both signs are negative as expected.

The presence of children has generally a positive effect, especially when the results are significant. The interactions between jobless and other persons jobless in the family have negative signs and the highest impacts besides income itself. If another person in the household is jobless, there is some weak evidence for a negative effect of up to around $2.3 \%$ in 2008. This effect may be a psychological impact of unemployment on the interviewee, as income itself is already accounted for. If the interviewee himself is without a job and no one else is unemployed in the household, the probability effect is highly significant and may well exceed $16 \%$ depending on year and model. As income is accounted for, this effect might be a strong psychological effect of unemployment. If we compare the differences between the model in (2) and (4) with respect to the coefficient of the income dummy, we see an overestimation of the dummies' probability effect. This turns out to mainly coincide with the absence of the unemployment dummy. Putting things the other way around, we see an overestimation of the effects of unemployment, when omitting the income dummy in (3) as compared to (2). Interestingly, if another person in the household is additionally without a job, there is some evidence that this effect is mitigated in 2008. Nevertheless, in 1998 the FE models tell the opposite story. The former effect may be explained with an income comparison in the family, mitigating relative deprivation, or it might be a residual effect arising from the fact that at least two persons in the household are present to share the burden of unemployment. 
The four occupation dummies are to some extent complementary and may be interpreted in relation to fulltime employment. Participation in education has a weakly negative effect and may be explained with some unexplained correlation with age and lack of employment. The effect of being retired is mostly negative and mostly insignificant. Finally, part-time employment instead of full-time employment has a negative sign and being out of the labor force is mostly highly significant and negative. The linear probability models reveal a positive and strongly significant effect of around $1.4 \%$ to $2 \%$ for house ownership. It is not only a proxy for financial situation but also captures the effect of not paying rent, leaving a higher amount of household income for consumption.

The following three variables capture the degree of dependency of social transfers. The number of months receiving unemployment benefits is not significant, probably as we already controlled not only for income, but also for unemployment status. The number of months receiving unemployment assistance captures the presence of long term unemployment beyond the unemployment dummy. The effect is negative as expected and may be well over $10 \%$ if received at least 12 months. Social assistance is typically not unemployment related and has no significant effect in our models.

University degree or Abitur or vocational training have a weakly negative influence which may mirror higher expectations on income levels of the subgroups or potentially higher relative deprivation. Because of limited time variation, they were left out from the fixed effects estimations and they do not show significance in the cross section with one exception. Degree of disability and days spent ill last year are wealth proxies. While the degree of disability has a negative and significant effect in the cross sections, it partly vanishes in the panel estimations. Illness has an additional negative effect, especially significant in 2008. In model (2) of 2008 the effect of 8 weeks of illness is $-1.8 \%$. The last eight controls only appear in the cross sectional estimations. While they are mostly not significant, their values are also strongly erratic with changing signs. The fact that death is significantly positive in both years is merely a coincidence and typically does not apply to the other years analyzed. Because of this, these controls were not used in the fixed effects models. Year dummies were also included, but they were never significant and are not listed. 
Figures $6 \mathrm{a}-\mathrm{b}$ show the complete estimated SDPL time series. The left figure shows that all models yield similar time series with a very similar time trend compared to the time series of the official poverty line. The right figure shows the SDPL in terms of median income percentages. The values fluctuate nicely around the definition of the European Commission, meaning that this poverty line explains income dissatisfaction best among all potential poverty line definitions. If we take a look at Figure 7a, we see that the fixed effects estimation yields lower marginal probability effects at the poverty line of around $10 \%$ for FE and $11 \%$ for FENLS, while the cross-section delivers $13.5 \%$ for LPM and $14.5 \%$ for NLS. It may be assumed here that cross sectional models overestimate the effects by not accounting for individual heterogeneity.

— Figure 7 around here -

\subsection{The Poverty Transition Region}

The nonlinear least squares approach is a generalization of the grid search method and it is not restricted to a search grid that almost surely misses global maxima on its uncountable superset $\mathbb{R}$. While this problem should only be minor in practice, the nonlinear least squares method also adds a straightforward way to statistically test for the maximum's location. Furthermore, it adds a degree of freedom to the characterization of poverty as it includes a jump length dimension of the local smoothing function. This dimension can be used to check whether the state change to poverty is discrete as assumed by the dummy grid search construction or whether there is a poverty transition region (PTR).

Both the NLS and FENLS procedures were carried out in two independent settings. ${ }^{42}$ The first one involved the estimation of the location by fixing the length of the PTR to a small,

\footnotetext{
${ }^{42}$ This strategy avoids an arbitrary restriction for the smooth function to be local in the NLS context when the PTR's length and location are estimated simultaneously. Generally, a smooth function stretched on the full income spectrum yields a better fit than its local counterpart and may therefore be favored by the iteration procedure. Nevertheless, a better global fit does not indicate the non-existence of a meaningful local smooth, it only prevents the single step procedure to find it.
} 
but feasible value. ${ }^{43}$ The purpose here was to underline the linear findings of the grid search, where PTR lengths of zero were assumed, and to obtain standard errors for the locations. Location results were already shown in the last subsection. The standard errors obtained are between 2 and 5 Euros in the NLS case and 2 and 8 Euros in the FENLS case with exception of 1990, where it is as big as 80 Euros. These standard errors underline that the estimation of the SDPL locations are rather precise.

The second setting starts with pre-estimated SDPLs based on the LPM and FE procedures respectively. The aim here is to assess the local behavior of the transition. To calculate a confidence intervall for the PTR's length, a two stage bootstrap is performed involving both the pre-estimation of the location and the nonlinear procedure. The results for the length of the PTR are given in Figure $7 \mathrm{~b}$. The estimates based on the original sample are reported along with the 90th centiles of the empirical distributions of the estimators derived from the bootstrap procedure. The estimates are almost always below 100 Euros and under 50 Euros in over two third of the cases. The results cannot be statistically distinguished from any low value, so there is no evidence in this setting against the assumption that the PTR is vanishingly short and that the search for a non-fuzzy poverty line is justified.

\section{Poverty Lines in European Countries}

While results based on German data suggest that the SDPL is temporally stable and consistent with a constant percentage point of the median income, it is interesting to investigate whether this result applies more generally in a cross-country comparison. To take a closer look, we use the ECHP. In contrast to the SOEP, the ECHP contains a question about the satisfaction with the financial situation in general instead of the more specific income satisfaction. As this makes a more rigid control for the household's financial situation necessary, we apply the FE panel approach only, netting out the influence of wealth, given its assumed time constancy. Also, satisfaction is only measured on a 6-point scale here as compared to the 11-point scale of the SOEP. Additionally, there are fewer observations at country level. Nevertheless, the results can be useful to draw an international map on approximate SDPL estimates.

\footnotetext{
${ }^{43}$ The value was chosen to be 20 Euros. As a robustness check, 7 different starting points were used and in cases of different estimation outcomes the one with the smallest RSS was chosen.
} 
In Figure 8 we present the estimated country specific poverty lines, based on country-wise fixed effects estimation. The estimated maxima are plotted along with $95 \%$ bootstrap confidence intervals. ${ }^{44}$ In addition, results based on the British Household Panel Survey (BHPS) 1994-2001 and on the SOEP 1994-1996 are shown for comparison.

The country specific SDPLs can be found in a range of $32.27 \%$ for Portugal and $64.71 \%$ in Finland. In addition to Portugal the Mediterranean countries Italy (40.02\%), Greece $(44.66 \%)$ and Spain (50.70\%) have rather low poverty lines. On the other hand, Denmark with its $44.85 \%$ has a significantly lower poverty line than Finland. The Benelux countries Luxembourg (56.06\%), Belgium (48.37\%) and the Netherlands (50.00\%) are relatively homogenous. Furthermore, Austria with its $55.48 \%$ belongs to the middle field. The estimate for Germany of around $52.30 \%$ is lower than the estimate based on the SOEP at around $60.83 \%$, but the former one is less exact and the two confidence intervals have a nonempty cross section, so the difference is not significant. As regards the data from the United Kingdom, the two results are only slightly different with $62.56 \%$ based on the ECHP and $67.58 \%$ based on the BHPS, with the difference being statistically insignificant. Finally, Ireland with its $62.71 \%$ is very similar to the United Kingdom.

In general, Figure 8 provides a heterogenous picture of poverty lines across Europe and may be interpreted as evidence against the hypothesis of a constant relative poverty line across European countries. In particular, there is indication that the SDPLs of Denmark, Belgium, Italy, Greece, Spain and Portugal may be lower than the $60 \%$ definition of Eurostat. This is not necessarily the view we would share a-priori. From a global point of view, all these countries belong to the group of developed countries and their additional spacial proximity may also suggest that their subjective understanding of poverty does not differ that much. ${ }^{45}$ If heterogeneity exists though as indicated, it is interesting to investigate its nature, e.g. whether it is systematic in a sense that it can be explained by the diversity among these countries in a macroeconomic, social and cultural manner.

\footnotetext{
${ }^{44}$ See Appendix A for how these bootstrap confidence intervals were computed.

${ }^{45} \mathrm{Also}$ note that in many cases, the differences across countries are not statistically significant.
} 
The differences among the countries are explored in more detail using a country panel based on 3-year subperiods. The dependent variable is taken to be the SDPL as a percentage point of the median for each country and year, while the independent variables are chosen to be macroeconomic characteristics. ${ }^{46}$ As we are also particularly interested in country level characteristics that do not vary or only slightly vary over time, we see fixed effects estimation as too restrictive and use pooled OLS (POLS) with regional indicators instead. As macroeconomic characteristics we take the Gini coefficient of disposable income, GDP per capita as purchasing power parity in Euros, employment as a share of the employed in the employable population by the ILO definition, grade of urbanization as a share of the population living in cities, life expectancy at birth and the age dependency ratio of the old ${ }^{47}$. Furthermore, we control for regions of Europe including Mediterranean, Benelux and Scandinavian countries and their complement as the reference group. All the macroeconomic variables are centered at the overall sample mean excluding GDP per capita, which is expressed as the deviation from the overall sample mean in percentage points.

\section{- Table 3 around here -}

The first regression (1) in Table 3 is a regular POLS with macroeconomic variables and regional indicators. In (2) the regional indicators are dropped to increase the degrees of freedom of the data. Regressions (3) and (4) are counterparts of (1) and (2) calculated with multiple imputation (MI) to fill in missing values of the Gini coefficient. ${ }^{48}$ To control for time effects we assume a linear time trend. ${ }^{49}$ As the number of observations is rather low, we performed stability checks by leaving out single countries from the regression to see whether

\footnotetext{
${ }^{46}$ These data were obtained from OECD StatExtract, Belgostat, the Central Statistics Office Ireland, Statistics Finland and Datastream.

${ }^{47}$ That is the population size over 65 divided by the population size between 15 and 65 years of age.

${ }^{48} \mathrm{About}$ one quarter of the Gini coefficients for the countries and points of time in use are missing. We contacted Eurostat, but there is no further data available at this time. The MI procedure used is the STATA implemented predictive mean matching. Robustness checks showed that other imputation methods lead to very similar results.

${ }^{49}$ Time dummies indicate that linearity is a good approximation and more importantly we save degrees of freedom for the estimations.
} 
the results are strongly influenced by the presence of a single country. Outcomes showed that this is not the case.

Taking a look at regression (1) and (2) we see that the coefficient of the Gini is negative and significant. An increase of the second decimal digit of the Gini by one goes along with a decrease of the SDPL by $1.6 \%$ in (1) and $1.3 \%$ points in (2) respectively. The fact that the regression coefficient of the Gini is negative, is a sign for inequality aversion. Countries with higher inequality typically harbor a higher share of the population with rather low income. Such countries have a tendency for a lower SDPL. The other way around, if a country has very low inequality, meaning that a high share of the population can be found around the median, the SDPL is typically a higher percentage of the median with a lower distance to the mid section as the population is more sparse in lower regions with a higher relative deprivation for those at the very bottom of the distribution.

The coefficient of per capita GDP is also negative and highly significant in all settings. Wealthier countries - proxied by GDP per capita - seem to go along ceteris paribus with a lower SDPL in relation to the median. This is in line with basic needs considerations, as it is easier for people to make ends meet in a wealthier society in terms of a given median income percentage, which is higher in absolute terms than in less wealthy societies.

These findings indicate that the SDPL concept has desirable cross country properties, as it can be expressed as a mixture of the absolutistic 'basic needs concept' and the concept of 'relative deprivation'. To put it in the words of Ravaillon and Chen (2011): "While we can agree that people care about their relative position in society (at least above some level of living), it is very hard to accept that they do not also care about their absolute levels of living (at least for all except very rich societies). More plausibly, utility is derived from both absolute income and relative income."

Nevertheless, there are other factors to look at to describe a wider range of heterogeneity among countries. For example, employment has a negative coefficient in all four models, 
being highly significant in (2) to (4). ${ }^{50}$ Higher employment is typically positively correlated with a higher wealth and the result may be interpreted similarly to the case of the GDP. Urbanization on the other hand exploits a positive and significant relationship with the SDPL in (2), else it is insignificant. This may weekly indicate that people living together in spatially condensed areas are more competitive and interpret poverty more in the relative sense in the direction of the median. The coefficient of life expectancy can be interpreted as a health indicator on societal level. It is always negative and it is significant in setting (4). This gives rise to the assumption that a healthier society is less concerned with income related issues of overall life satisfaction, being already satisfied with less income than in societies with lower health indicators. The age dependency ratio is an indicator for the countries' age structures. When its coefficient is significant, its sign is negative. As the ratio is high if the share of pensioners is high, a negative sign may indicate that pensioners tend to think more in absolute terms about their income and that they are satisfied with a lower amount. Also the thinking, the elderly may be less 'competitive', is similarly in line with this finding. As regards general time trends, the estimates are highly insignificant in all cases. This is an indication for the SDPL being time stable between 1994 and 2001 in the region in scope.

Along with the variables just mentioned, we use controls for Mediterranean, Benelux and Scandinavian countries to capture further unspecified time constant effects. Results show that in (1) the coefficients of Benelux and Scandinavian are significant and positive, indicating higher SDPLs than in central European countries. After MI though, (3) shows no significance any more. Why $(3)$ is more in line with the actual findings may be seen when looking at the coefficient of the Scandinavian countries. As we saw before, Denmark and Finland had very different SDPLs, a rather low and a rather high one, so it is more intuitive that the coefficient is insignificant. Thus, (3) indicates that with the amount of data we have at hand, differences are well-explained with the set of macroeconomic variables chosen above and that regional fixed effects have no additional explanatory power.

\footnotetext{
${ }^{50}$ The tendency towards insignificance is generally higher in (1), as due to the higher number of regressors model (1) has less power to reject the null.
} 


\section{Conclusion}

This paper defines the satisfaction-driven poverty line as to maximize the relationship between poverty status and income dissatisfaction, based on the simple assumption that the true poverty status has the unique property of explaining income dissatisfaction best in any proper econometric setting. Application to data from the German Socio-Economic Panel yields a time stable poverty line similar to the definition provided by the Statistical Office of the European Commission as $60 \%$ of the median income. Our results characterize this definition of poverty as the best dichotomization to explain the relationship between income and income dissatisfaction measured by the subjective psychological variable of income satisfaction.

The results suggest that our approach is generally applicable and that estimation of the SDPL may serve as a unified strategy for poverty measurement across countries. Using data from the European Community Household Panel, additional evidence for satisfaction-based poverty lines and their cross-country differences were presented. The results further indicate that although the static 60\%-definition is in line with the SDPL in Germany, the SDPLs of other European countries may be different. Analysis of the differences among European SDPLs suggests on the one hand that national poverty lines can be explained by the income inequality of the country in form of inequality aversion, resulting in poverty lines that are higher percentages of the median, when inequality is lower. On the other hand, the percentage points fall with higher wealth as basic needs are already satisfied with an income at a lower percentage of the median, if a country is wealthier.

In addition to this, the proposed approach also allows one to test whether the poverty line exists as a discrete phenomenon, or whether a fuzzy poverty line is more appropriate. Our analysis for Germany suggests that the state change to poverty is rather discrete, so that poverty line definitions rather than definitions of poverty transition regions are more appropriate. 


\section{References}

Abrams, M. (1973). "Subjective Social Indicator," Social Trends 4, (HMSO, London), 35-50.

Atkinson, A.B. and F. Bourguignon (2001). "Poverty and Inclusion from a World Perspective," in: J. Stiglitz and P.-A. Muet (eds) "Governance, Equity and Global Markets," Oxford: Oxford University Press.

Belgostat (http://www.nbb.be/belgostat/PresentationLinker?Tableld=527000090\&Lang=E). Accessed January 2012.

Belhadj, B. (2011). "New fuzzy indices of poverty by distinguishing three levels of poverty," Research in Economics, vol. 65(3), 221-231.

Blanchflower, D.G. and A.J. Oswald (2004). "Well-Being Over Time In Britain And The USA," Journal of Public Economics, vol. 88, 1359-1386.

Blanchflower, D.G. and A.J. Oswald (2008). "Is well-being U-shaped over the life cycle?" Social Science Medicine, vol. 66(8), 1733-1749.

Boes, S. and R. Winkelmann (2010). "The Effect of Income on General Life Satisfaction and Dissatisfaction," Social Indicators Research, vol. 95(1), 111-128.

Brickman, P., D. Coates and R. Janoff-Bullman (1978) "Lottery Winners and Accident Victims: Is Happiness Relative?" Journal of Personality and Social Psychology, vol. 36(8), 917-27.

Central Statistics Office Ireland (http://www.cso.ie/en/media/csoie/releasespublications/ documents/silc/2010/prelimsilc_2010.pdf). Accessed January 2012. 
Chamberlain, G. (1980). "Analysis of Covariance with Qualitative Data," Review of Economic Studies, 47, 225-238.

Clark, A.E. and A.J. Oswald (1996). "Satisfaction and Comparison Income," Journal of Public Economics, vol. LXI, 359-381.

Clark, A.E. and C. Senik (2010). "Who compares to whom? The anatomy of income comparisons in Europe," Economic Journal, vol. 120, 573-594.

D'Ambrosio, C. and J.R. Frick (2007). "Income Satisfaction and Relative Deprivation: An Empirical Link," Social Indicators Research, vol. 81, 497-519.

Danziger, S., J. van der Gaag, M.K. Taussig and E. Smolensky (1984). "The Direct Measurement of Welfare Levels: How Much Does It Cost to Make Ends Meet?" The Review of Economics and Statistics, MIT Press, vol. 66(3), 500-505.

Datastream, Thomson Financial, access date: April 2nd 2012.

De Vos, K. and T.I. Garner (1991). "An Evaluation of Subjective Poverty Definitions: Comparing Results from the U.S. and the Netherlands," Review of Income and Wealth, Wiley Blackwell, vol. 37(3), 267-85.

Diener, E., E. Sandvik, L. Seidlitz and M. Diener (1993). "The relationship between income and subjective well-being: Relative or absolute?" Social Indicators Research, vol. 28, 195-223.

Diener, E., E.M. Suh, R.E. Lucas and H.L. Smith (1999), "Subjective well-being: Three decades of progress," Psychological Bulletin, vol. 125, 276-302.

Di Tella, R. and R. MacCulloch (2008). "Happiness Adaptation to Income beyond Basic Needs," NBER Working Papers 14539, National Bureau of Economic Research, Inc. 
European Commission (1999). ECHP UDB Manual, Bruxelles.

Ferrer-i-Carbonell, A. (2011). "Happiness economics", Els Opuscles del CREI, num. 28.

Ferrer-i-Carbonell, A. and P. Frijters (2004). "How important is methodology for the estimates of the determinants of happiness," The Economic Journal, vol. 114, 641-659.

Ferrer-i-Carbonell, A. and B. van Praag (2009). "Do people adapt to changes in income and other circumstances?", unfinished manuscript, source http://ferrer.iaecsic.org/Adaptation\&IncomeChanges.pdf, access date: August 2011.

Frank, R. H. (2005). "Does Absolute Income Matter?" in P. L. Porta and L. Bruni, eds., Economics and Happiness, Oxford University Press, 2005.

Frey, B.S. and A. Stutzer (2002). "What Can Economists Learn from Happiness Research?" Journal of Economic Literature, vol. 40(2), 402-435.

Fuchs, V. (1967). "Redefining poverty and redistributing income", The Public Interest, vol. 8, 88-95.

Goedhart, T., V. Halberstadt, A. Kapteyn and B.M.S. van Praag (1977). "The poverty line: Concept and measurement," Journal of Human Resources, 12, 503-520.

Hagenaars, A.J.M. and B.M.S. van Praag (1985). "A Synthesis of Poverty Line Definitions," Review of Income and Wealth, vol. 31(2), 139-54.

Haisken-DeNew, J.P. and J.R. Frick (2005). "The Desktop Companion to the German Socio-Economic Panel study," Version 8.0, DIW Berlin, Germany. 
Headey, B. and M. Wooden (2004). "The effects of wealth and income on subjective well-being and ill-being." The Economic Record, vol. 80, 24-33.

Huppert, F.A. and J.E. Whittington (2003). "Evidence for the independence of positive and negative well-being: Implications for quality of life assessment," British Journal of Health Psychology, vol. 8, 107-122.

Kahneman, D. (1999). "Objective happiness," in: Kahneman D., E. Diener and N. Schwarz (eds.): "Well-being: Foundations of hedonic psychology," 3-25. New York: Russell Sage Foundation Press.

Kapteyn A., P. Kooreman, R. Willemse (1988). "Some Methodological Issues in the Implementation of Subjective Poverty Definitions," Journal of Human Resources, University of Wisconsin Press, vol. 23(2), pages 222-242.

Krämer, W. (1994). "Statistische Probleme bei der Armutsmessung: Gutachten im Auftrag des Bundesministiums für Gesundheit," Baden-Baden: Nomos Verl.-Ges.

Kroh, M. (2005). "Surveying the Left-Right Dimension: The Choice of a Response Format," Discussion Papers of DIW Berlin 491, DIW Berlin, German Institute for Economic Research.

Luttmer, E. F. P. (2005). "Neighbors as Negatives: Relative Earnings and Well-Being," Quarterly Journal of Economics vol. 120(3), 963-1002.

Maddala, G. S. (1983). "Limited-dependent and qualitative variables in econometrics," Cambridge: Cambridge University Press.

McLachlan, G. and D. Peel (2000). "Finite Mixture Models," John Wiley \& Sons.

Mentzakis, E. (2011). "Allowing for heterogeneity in monetary subjective well-being valuations," Health Economics, vol. 20(3), 331-347. 
OECD StatExtract (http://stats.oecd.org/Index.aspx). Accessed January 2012.

Ravallion, M. (2010). "Poverty Lines across the World," Policy Research Working Paper 5284, World Bank.

Ravallion, M. and S. Chen (2011). "Weakly Relative Poverty," The Review of Economics and Statistics, vol. 93(4), 1251-1261.

Ravallion, M., S. Chen and P. Sangraula (2008). "Dollar a day revisited," Policy Research Working Paper Series 4620, World Bank.

Sandvik, E., E. Diener, and L. Seidlitz (1993). "Subjective well-being: The convergence and stability of self-report and non-self-report measures," Journal of Personality, vol. 61, 317-342.

Statistics Finland (http://www.stat.fi/til/tjt/2009/tjt_2009_2011-05-20_tau_002_en .html). Accessed January 2012.

Steptoe, A. and J. Wardle (2005). "Positive affect and biological function in everyday life", Neurobiology of Aging, Suppl. 1, 108-112.

Terza, J.V. (1985). "Reduced-Form Trinomial Probit: A Quantal Response Model without a Priori Restrictions," Journal of Business \& Economic Statistics, vol. 3(1), 54-59.

Urry H. L., J. B. Nitschke, I. Dolski, D. C. Jackson, K. M. Dalton, C. J. Mueller, M. A. Rosenkranz, C. D. Ryff, B. H. Singer and R. J. Davidson (2004). "Making a life worth living: Neural correlates of well-being", Psychological Science, 15, 367-72.

Van Praag, B.M.S. (1991). "Ordinal and cardinal utility: an integration of the two dimensions of the welfare concept," Journal of Econometrics, vol. 50, 69-89. 
Wagner, G. G. (2007). "Wie die 11er-Skala in das SOEP kam - Ein Beitrag zu den Problemen und Möglichkeiten multidisziplinärer Forschung und zugleich eine Fußnote zum Design der SOEP-Stichprobe," in Schwarze et al. (eds): Arbeitsmarkt- und Sozialpolitikforschung im Wandel - Festschrift für Christof Helberger zum 65. Geburtstag.

Wagner, G. G., J. R. Frick, and J. Schupp (2007). "The German Socio-Economic Panel Study (SOEP) - Scope, Evolution and Enhancements," Schmollers Jahrbuch 127, no. 1, 139-169.

Winkelmann, L. and R. Winkelmann (1998). "Why Are the Unemployed So Unhappy? Evidence from Panel Data," Economica, vol. 65(257), 1-15.

Wooldridge, J. M. (2002). "Econometric Analysis of Cross Section and Panel Data," MIT Press.

World Bank (1990). "World Development Report: Poverty," New York: Oxford University Press. 


\section{Appendix A}

When the bootstrap is applied to the SDPL based on grid search, the problem emerges that in some resamples the secondary maximum - also observable in Figures 3 and 4 - is coincidentally larger than the maximum of interest (the one in the poverty region). In order to adress this problem, we use a two-step strategy. In a first step we resample the data to obtain a bootstrap distribution of the maxima of the FE estimates' $R^{2}$-s. In the second step we estimate a finite mixture model given the bootstrap based maxima. In this way, we can control for observation disturbances caused by secondary and sometimes tertiary maxima that are inferior in the original sample, but deliver global maxima in some resamples and are thus handled as observation disturbances that prevent us from observing the position of the primary maximum. This situation suggests a latent class setting. A finite mixture distribution is then given as follows:

$$
f_{\text {mix }}(x)=\sum_{d=1}^{D} \pi_{d} \cdot \phi\left(x \mid \mu_{d}, \sigma_{d}\right), \quad \phi(. \mid \mu, \sigma) \sim \mathbb{N}(\mu, \sigma) .
$$

In almost all cases $D=2$ and $D$ is never greater than 3 . We estimate via the STATA addon $\mathrm{fmm}^{51}$ using maximum likelihood. As confidence intervals we report the $95 \%$ confidence intervals of the normal distribution the original maximum $m$ belongs to with highest a-posteriori probability $\max _{i \in\{1, \ldots, D\}} \tau_{i}(m)$, given ${ }^{52}$

$$
\tau_{i}\left(m \mid \pi_{1} \ldots \pi_{D}, \mu_{1} \ldots \mu_{D}, \sigma_{1}, \ldots, \sigma_{D}\right)=\pi_{i} \phi\left(m \mid, \mu_{i}, \sigma_{i}\right) / \sum_{d=1}^{D} \pi_{d} \phi\left(m \mid \mu_{d}, \sigma_{d}\right)
$$

${ }^{51}$ The addon was programmed by Partha Deb, Hunter College and the Graduate Center, City University of New York, USA partha.deb@hunter.cuny.edu.

${ }^{52}$ For more on finite mixture models see McLachlan and Peel (2000). 


\section{Appendix B}

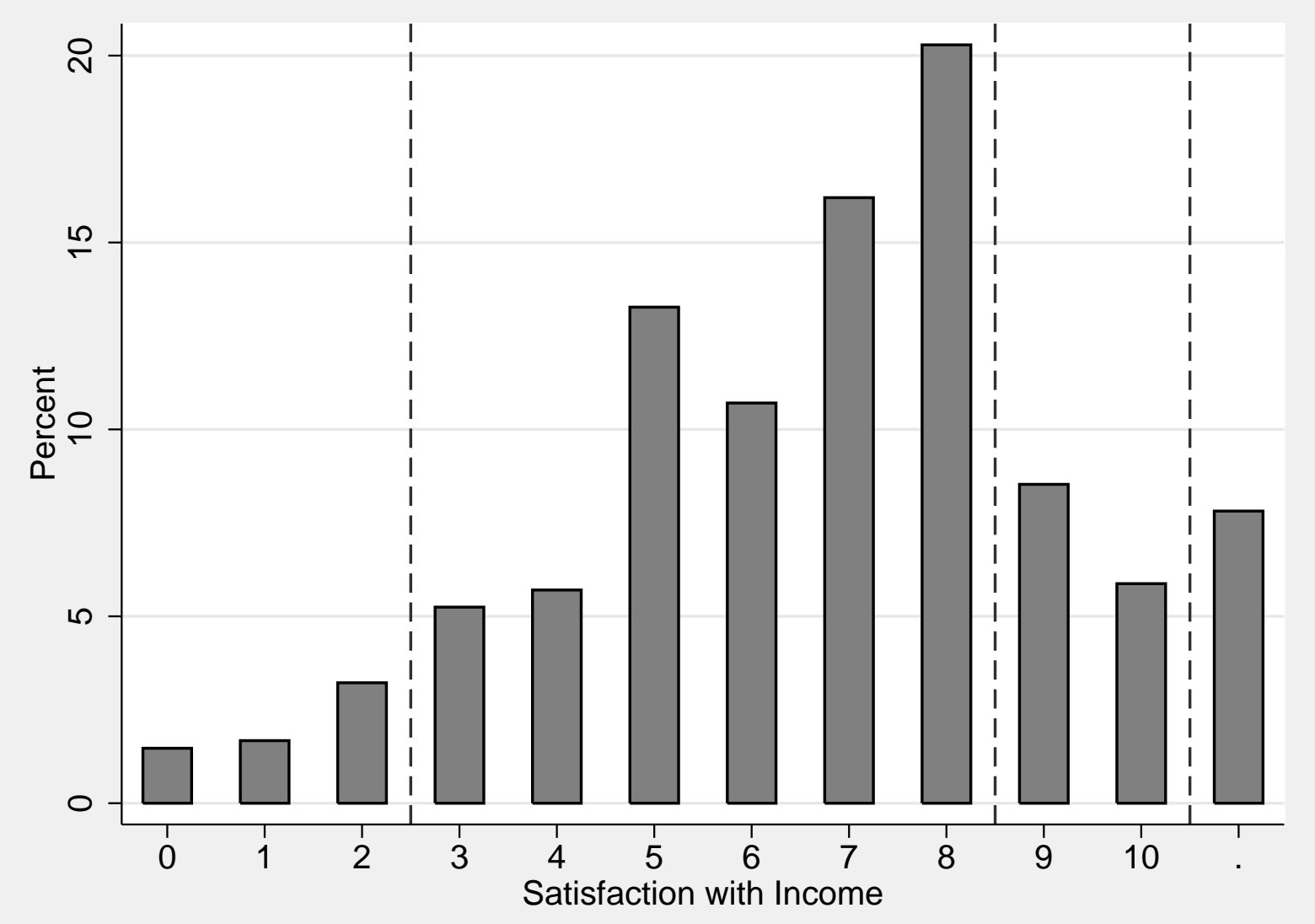

Figure 1 - Distribution of answers to the SOEP income satisfaction question in 2009. Dashed lines separate the three sections outlined by the questionnaires formulation and the missing values.

Own calculations. 


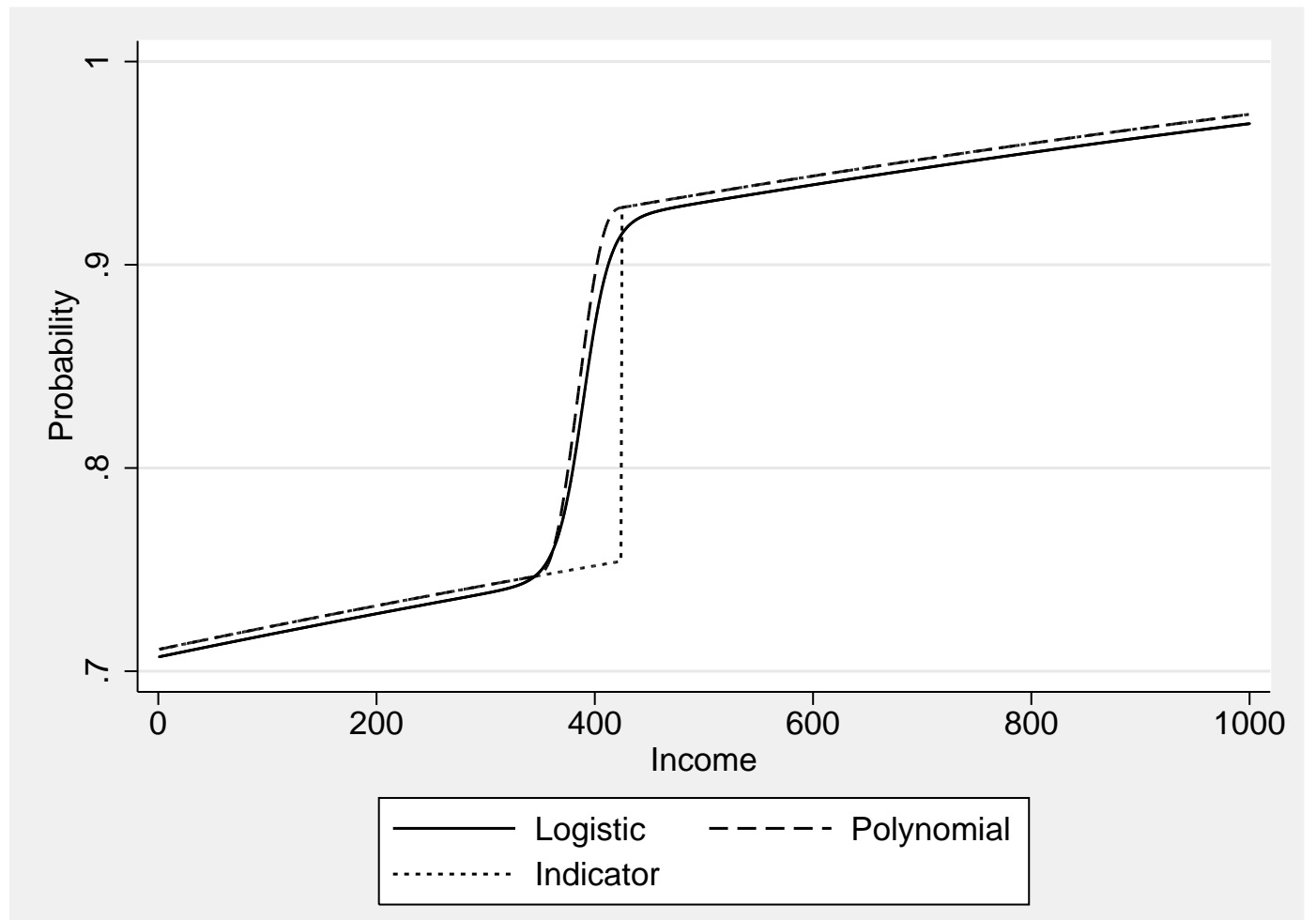

Figure 2 - Illustrative example of the indicator smoothing concept applied to the relationship between income satisfaction and income based on real SOEP data of the year 1985. Here the jump function is combined with a third degree polynomial. Own calculations. 

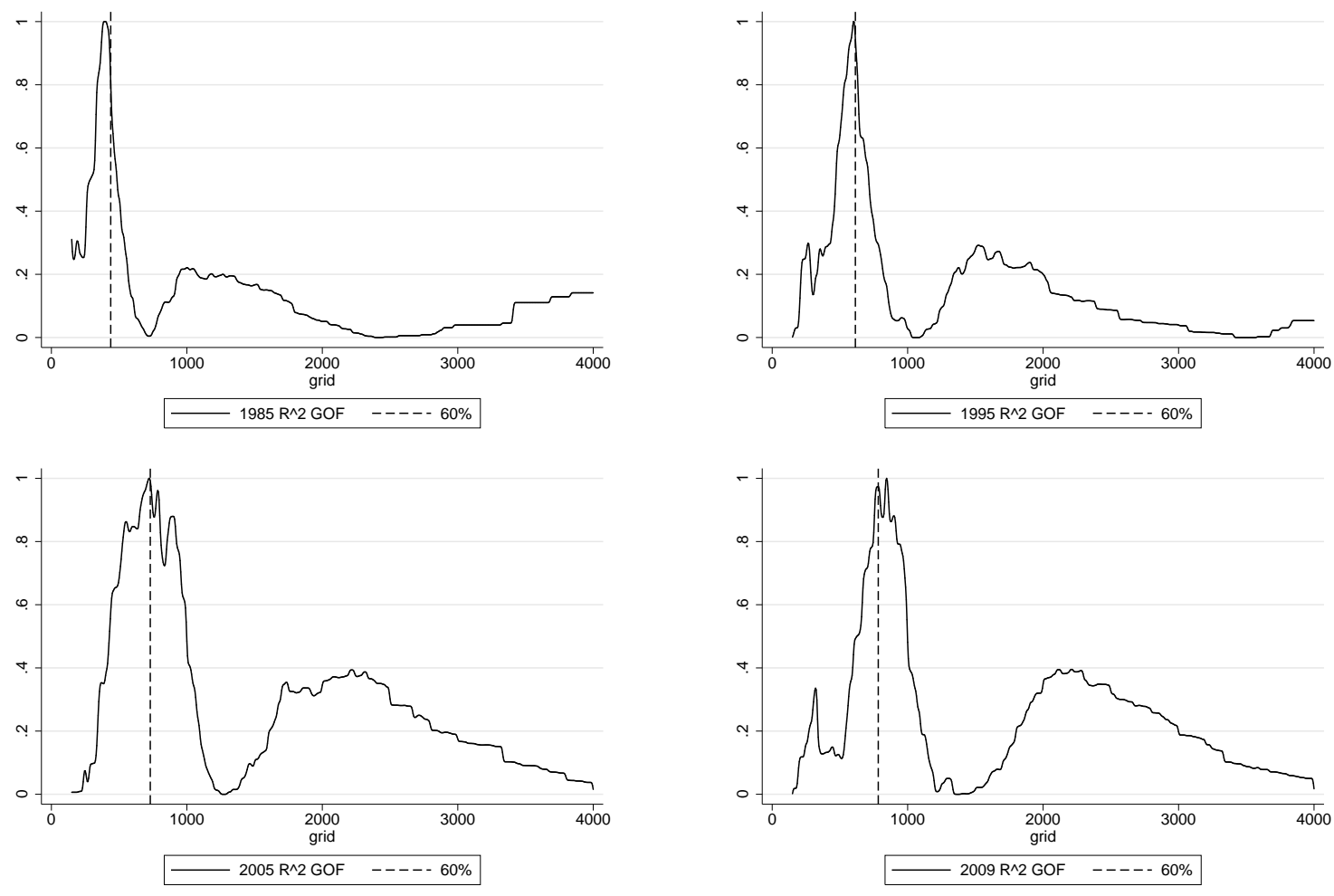

Figure 3 - Grid search results in 5 Euro steps using the linear probability model. Baseline is set as the R-squared of regressions without dummy. The highest value is normalized to 1 . Top left (a) result for 1985, top right (b) for 1995, bottom left (c) for 2005 and bottom right (d) for 2009. Own calculations. 

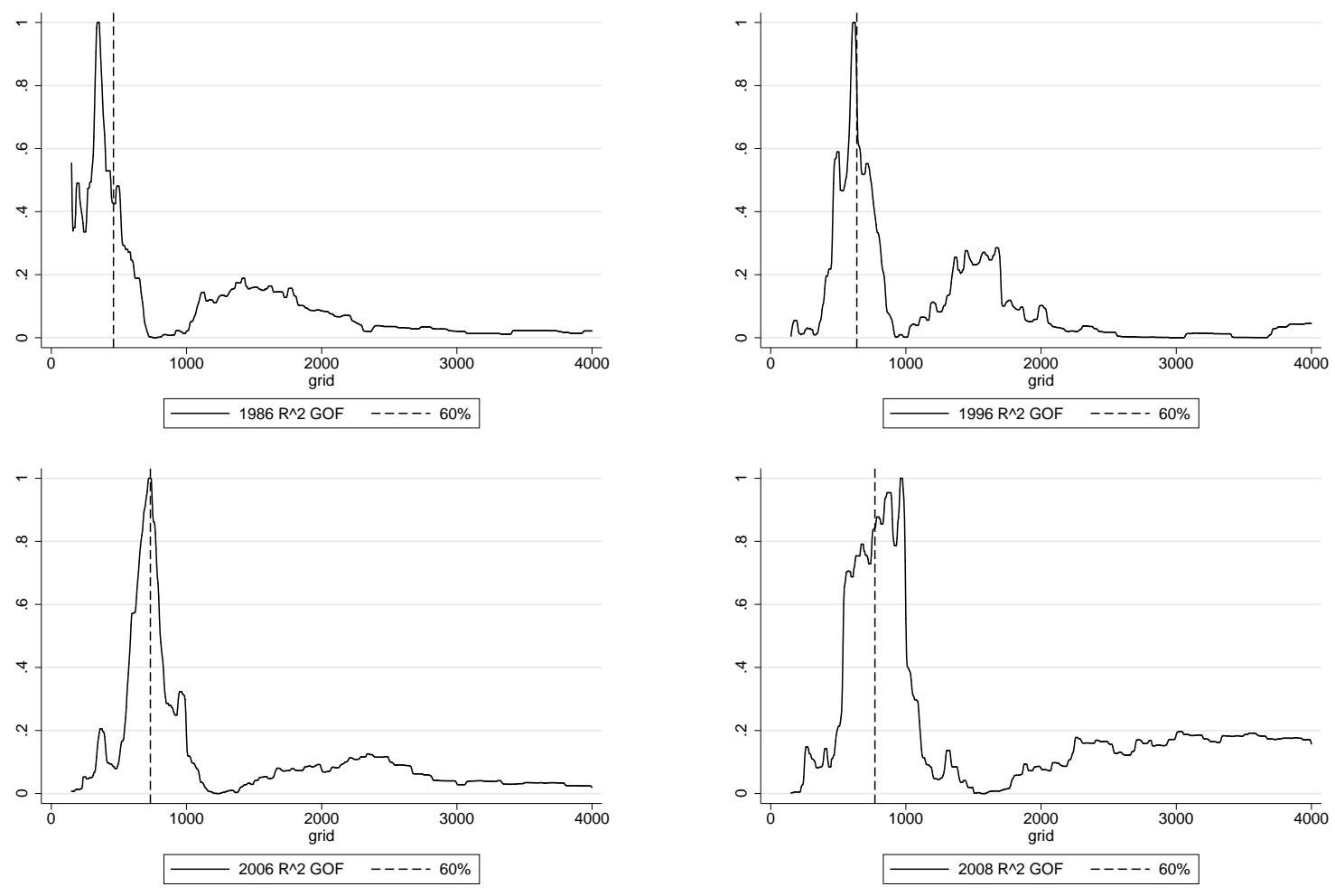

Figure 4 - Grid search results in 5 Euro steps using the 3-years fixed effects panel model. Baseline is set as the R-squared of regressions without dummy. The highest value is normalized to 1 . Top left (a) result for 1985-1987, top right (b) for 1995-1997, bottom left (c) for 2005-2007 and bottom right (d) for 2007-2009. Own calculations. 


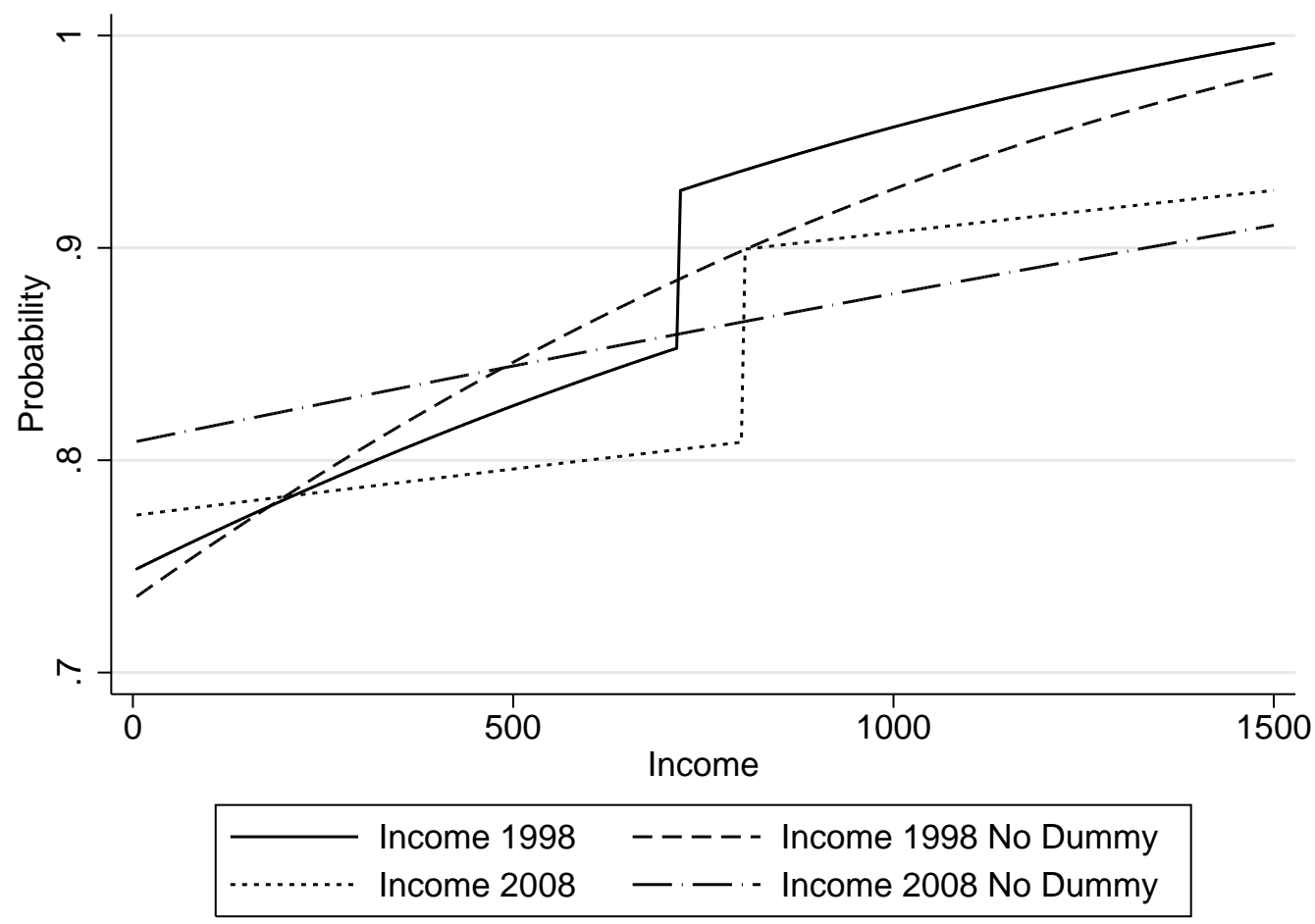

Figure 5 - Probability plots for not being dissatisfied with income based on fixed effects estimation with and without the income dummy variable. The plots are valid for a reference person with zero valued control variables as in Table 2, models (2) and (3). Own calculations.
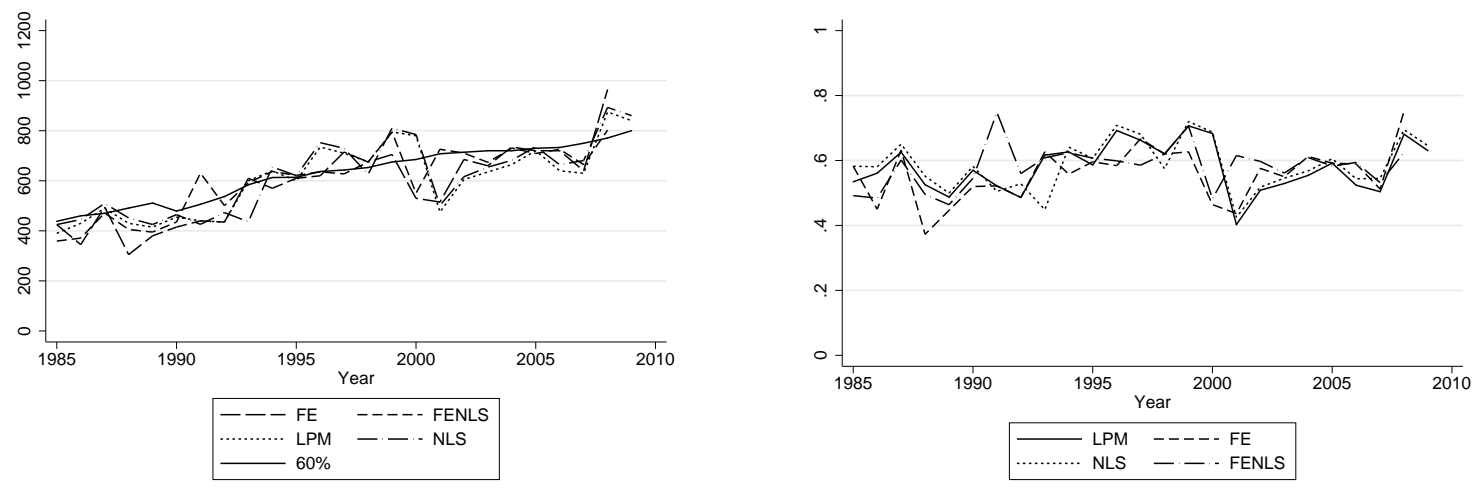

Figure 6 - Time series: SDPLs based on LPM, FE, NLS and FENLS estimations and the $60 \%$ poverty line. Left (a) in Euros, right (b): as median percentage. Own calculations. 

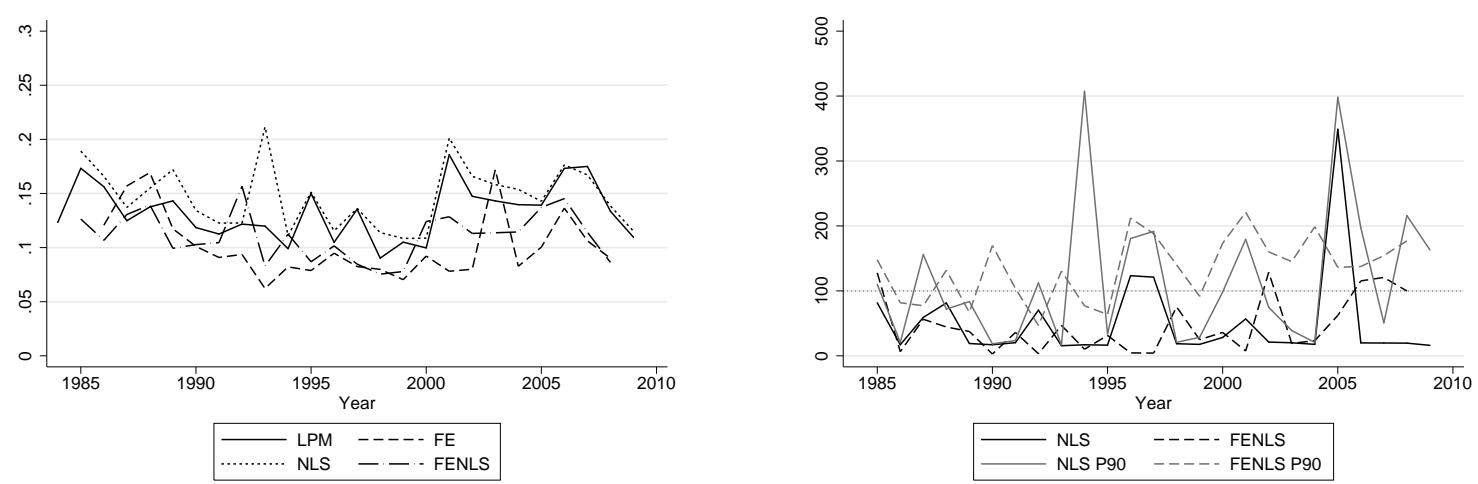

Figure 7 - Left (a): Time series of the (marginal) probability effect of the PTR transition based on the LPM, FE, NLS and FENLS estimations. A single outlier in 1989 was set to the bootstrap mean for the FENLS. Right (b): Time series of the length of the PTR based on NLS and FENLS estimations and their one sided percentile based bootstrap $90 \%$ confidence intervals. Outliers in 1987, 1990, 2001 for the NLS were set to their bootstrap means. Own calculations.

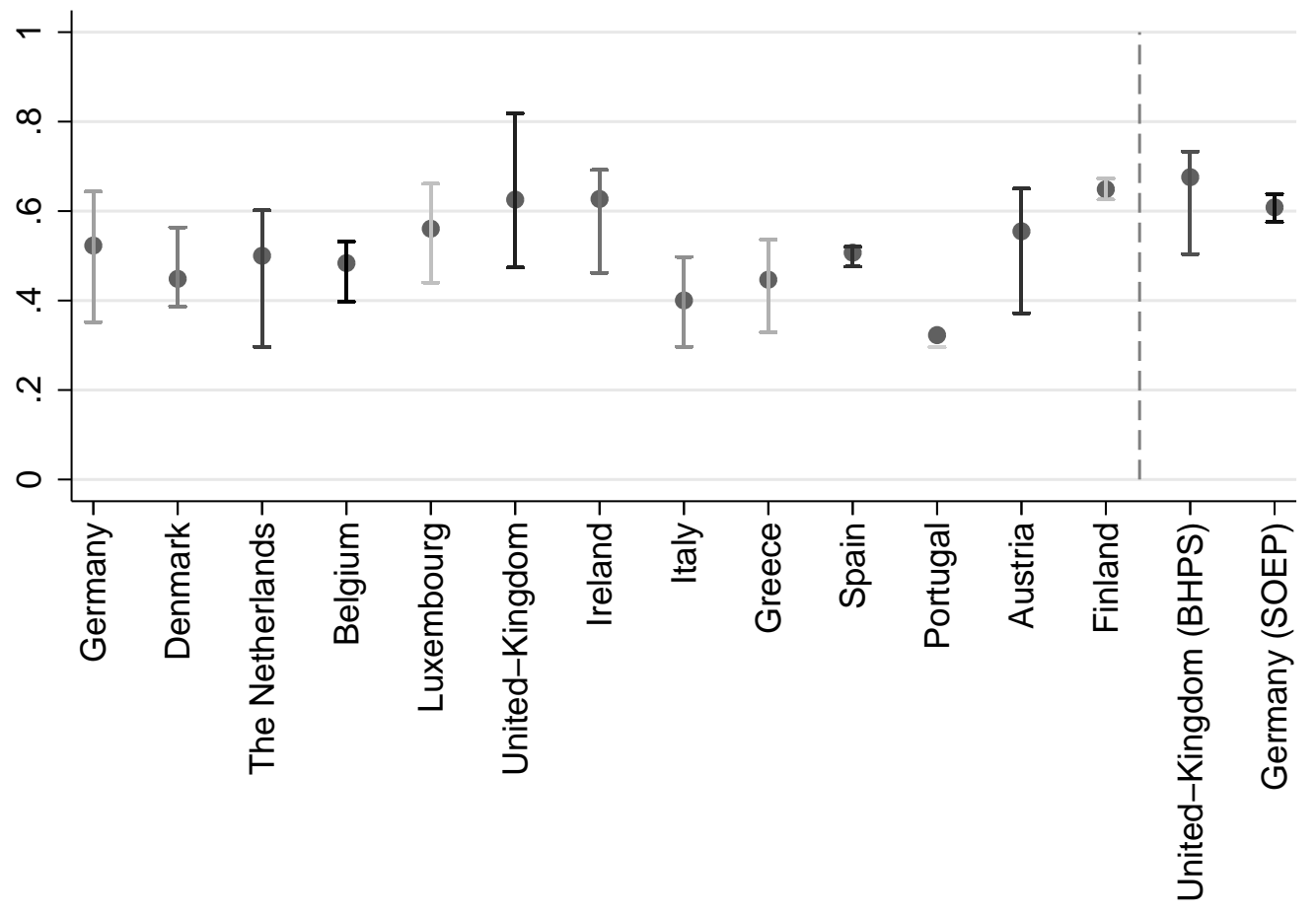

Figure 8 - Fixed Effects SDPL poverty lines based on the complete ECHP panel information. $95 \%$ confidence intervals are provided based on bootstrap estimation. Results based on the BHPS 1994-2001 and on the SOEP 1994-1996 are provided for comparison. Own calculations. 


\begin{tabular}{|c|c|c|c|c|}
\hline dep. var. : income satisfaction & (1) & $(2)$ & (3) & $(4)$ \\
\hline income & $.0002088 * * *$ & $.0001552 * * *$ & $.0002376 * * *$ & $.0001902 * * *$ \\
\hline income $^{2}$ & $-6.41 e-08 * * *$ & $-3.59 \mathrm{e}-08 * * *$ & $-5.69 e-08 * * *$ & $-4.29 \mathrm{e}-08 * * *$ \\
\hline income $^{3}$ & $5.69 \mathrm{e}-12 * * *$ & $2.00 \mathrm{e}-12 * * *$ & $3.24 \mathrm{e}-12 * * *$ & $2.25 \mathrm{e}-12 * * *$ \\
\hline incdum & $.0902269 * * *$ & $.0799031 * * *$ & & $.0873776^{* * *}$ \\
\hline married & $.0475478 * * *$ & -.0005017 & $6.54 \mathrm{e}-06$ & \\
\hline separated & $-.0890270 * *$ & -.0265090 & -.0270401 & \\
\hline sex & $.0104854 *$ & & & \\
\hline age & $-.0046393 * * *$ & & & \\
\hline $\operatorname{age}^{2}$ & $.0000521^{* * *}$ & -.0000744 & -.0000708 & \\
\hline e & $-.0179378 * *$ & & & \\
\hline child $0-3$ & .0163940 & -.0053448 & -.0011421 & \\
\hline child 4-11 & .0080097 & $.0365091 * *$ & $.0381299 * *$ & \\
\hline child 12-17 & $.0226381 * * *$ & $.0288710^{* * *}$ & $.0289072 * * *$ & \\
\hline \multicolumn{5}{|l|}{ jobless $X$ jobless other } \\
\hline 01 & -.0041254 & -.0024654 & -.0025651 & \\
\hline 10 & $-.1467259 * * *$ & $-.1056438 * * *$ & $-.1100456 * * *$ & \\
\hline 11 & $-.1323874 * * *$ & $-.1583044 * * *$ & $-.1674143^{* * *}$ & \\
\hline in education & -.0096857 & $-.0317808 * *$ & $-.0308935 * *$ & \\
\hline retired & $-.0002229 *$ & -.0232619 & -.0199658 & \\
\hline part-time & .0032601 & $-.0316423 *$ & $-.0313248 *$ & \\
\hline out of labor force & -.0238282 & $-.0781198 * * *$ & $-.0787139 * * *$ & \\
\hline owner & $.0213148 * * *$ & & & \\
\hline months unempl. benefits & -.0017560 & .0007395 & .0008081 & \\
\hline months unempl. assistance & -.0058263 & $-.0078976 * *$ & $-.0080673^{* * *}$ & \\
\hline months social assistance & -.0030641 & .0015851 & .0010559 & \\
\hline university & $-.0232552 * *$ & & & \\
\hline abitur/voc. training & -.0096111 & & & \\
\hline disability degree & $-.0002323^{*}$ & .0000624 & .0000258 & \\
\hline ill & $-.0003014^{*}$ & $1.25 \mathrm{e}-08$ & $-4.74 e-06$ & \\
\hline newborn & $-.0943048 *$ & & & \\
\hline newly married & $-.0582913^{* *}$ & & & \\
\hline newly disabled & -.0338399 & & & \\
\hline new death & $.0840644 * * *$ & & & \\
\hline newly divorced & $-.2116805^{* *}$ & & & \\
\hline new child u14 left & -.0373934 & & & \\
\hline soon divorced & .0673761 & & & \\
\hline soon married & $.0676058 * * *$ & & & \\
\hline cons & $.7468746^{* * *}$ & $.9253191 * * *$ & $.9192893 * * *$ & $.6858231^{* * *}$ \\
\hline Observations & 13151 & 35771 & 35771 & 35771 \\
\hline$R^{2}$ & 0.1316 & 0.0390 & 0.0341 & 0.0247 \\
\hline Location of Maximum & 675 & 675 & - & 675 \\
\hline
\end{tabular}

Table 1 - Year 1998, income satisfaction dummy as regressand. (1) LPM with the best income dummy fit, (2) 3-years FE panel model with the best income dummy fit, (3) as (2) without dummy and (4) as (2) without additional controls. Robust standard errors. Own calculations. 


\begin{tabular}{|c|c|c|c|c|}
\hline dep. var. : income satisfaction & (1) & $(2)$ & (3) & $(4)$ \\
\hline income & $.0000527 * * *$ & $.0000437 * * *$ & $.0000795 * * *$ & $.0000530 * * *$ \\
\hline income $^{2}$ & $-3.55 \mathrm{e}-09 * * *$ & $-2.61 e-09 * * *$ & $-4.70 \mathrm{e}-09 * * *$ & $-3.09 \mathrm{e}-09 * * *$ \\
\hline income $^{3}$ & $2.37 \mathrm{e}-12 * * *$ & $3.23 e-14 * * *$ & $5.79 \mathrm{e}-14 * * *$ & $3.78 \mathrm{e}-14 * * *$ \\
\hline incdum & $.1337918^{* * *}$ & $.0900829 * * *$ & & $.1010768 * * *$ \\
\hline married & $.0219009 * * *$ & .0271412 & .0139223 & \\
\hline separated & -.0000279 & .0329272 & .0369348 & \\
\hline $\operatorname{sex}$ & $.0115466^{*}$ & & & \\
\hline age & $-.0072594 * * *$ & & & \\
\hline $\operatorname{age}^{2}$ & $.0000676 * * *$ & -.0000358 & -.0000437 & \\
\hline e & -.0061185 & & & \\
\hline child $0-3$ & $.0391889 * * *$ & $.0484145^{* * *}$ & $.0519664 * *$ & \\
\hline child 4-11 & .0095827 & .0223486 & .0239098 & \\
\hline child 12-17 & .0090761 & .0059450 & .0074916 & \\
\hline \multicolumn{5}{|l|}{ jobless $X$ jobless other } \\
\hline 01 & -.0105735 & -.0196849 & -.0230573 & \\
\hline 10 & $-.1265161^{* * *}$ & $-.1656058 * * *$ & $-.1752323 * * *$ & \\
\hline 11 & -.0376719 & $-.1406440 * * *$ & $-.1559932 * * *$ & \\
\hline in education & -.0122396 & -.0179335 & -.0212733 & \\
\hline retired & .0211099 & -.0202260 & -.0223186 & \\
\hline part-time & -.0081407 & -.0261201 & $-.0299941^{*}$ & \\
\hline out of labor force & .0065805 & $-.1089817^{* * *}$ & $-.1130105^{* * *}$ & \\
\hline owner & $.0135794 * *$ & & & \\
\hline months unempl. benefits & -.0053308 & .0025754 & .0024671 & \\
\hline months unempl. assistance & $-.0083573^{* * *}$ & .0017857 & .0020511 & \\
\hline months social assistance & -.0060898 & .0014436 & .0009512 & \\
\hline university & -.0042473 & & & \\
\hline abitur/voc. training & -.0009225 & & & \\
\hline disability degree & $-.0004776 * * *$ & $.0005772 *$ & $.0005917^{*}$ & \\
\hline ill & $-.0004839 * *$ & $-.0003344 * *$ & $-.0003449 * *$ & \\
\hline newborn & -.0608937 & & & \\
\hline newly married & -.0013687 & & & \\
\hline newly disabled & .0027484 & & & \\
\hline new death & $.0965823^{* * *}$ & & & \\
\hline newly divorced & -.0020439 & & & \\
\hline new child u14 left & $.0501440 * *$ & & & \\
\hline soon divorced & -.1353558 & & & \\
\hline soon married & -.0778485 & & & \\
\hline cons & $.8866412 * * *$ & $.8850434 * * *$ & $.9270529 * * *$ & $.7641366^{* * *}$ \\
\hline Observations & 17882 & 53704 & 53704 & 53704 \\
\hline$R^{2}$ & 0.1553 & 0.0395 & 0.0313 & 0.0213 \\
\hline Location of Maximum & 875 & 965 & - & 965 \\
\hline
\end{tabular}

Table 2 - Year 2008, income satisfaction dummy as regressand. (1) LPM with the best income dummy fit, (2) 3-years FE panel model with the best income dummy fit, (3) as (2) without dummy and (4) as (2) without additional controls. Robust standard errors. Own calculations. 


\begin{tabular}{|c|c|c|c|c|c|c|c|c|}
\hline \multirow[b]{2}{*}{ dep. var.: SDPL } & \multicolumn{2}{|c|}{$(1)$} & \multicolumn{2}{|c|}{$(2)$} & \multicolumn{2}{|c|}{ (3) } & \multicolumn{2}{|c|}{$(4)$} \\
\hline & coeff. & $\mathrm{P}$-value & coeff. & P-value & coeff. & P-value & coeff. & P-value \\
\hline Gini & $-1.548^{*}$ & 0.059 & $-1.287^{* *}$ & 0.017 & -1.060 & 0.171 & $-1.356^{* *}$ & 0.011 \\
\hline GDP per capita & $-0.186^{* *}$ & 0.048 & $-0.245^{* *}$ & 0.016 & $-0.317^{* * *}$ & 0.005 & $-0.297^{* * *}$ & 0.004 \\
\hline Employment & -0.280 & 0.470 & $-1.224^{* * *}$ & 0.002 & $-1.089^{* * *}$ & 0.006 & $-1.316^{* * *}$ & 0.001 \\
\hline Urban & -0.335 & 0.189 & $0.292^{*}$ & 0.074 & -0.021 & 0.913 & -0.222 & 0.142 \\
\hline Life Expectancy & -0.647 & 0.713 & -2.454 & 0.156 & -2.658 & 0.179 & $-2.999 *$ & 0.093 \\
\hline Age Dependency Ratio & 2.441 & 0.129 & $-2.245^{* * *}$ & 0.004 & -0.980 & 0.291 & $-2.209 * * *$ & 0.005 \\
\hline Mediterranean & -0.857 & 0.884 & & & -7.064 & 0.311 & & \\
\hline Benelux & $22.027^{* *}$ & 0.016 & & & 6.030 & 0.181 & & \\
\hline Scandinavian & $7.071^{*}$ & 0.051 & & & -0.089 & 0.988 & & \\
\hline Year & -1.443 & 0.262 & 0.642 & 0.512 & 0.249 & 0.781 & 0.633 & 0.496 \\
\hline cons & $46.428^{* * *}$ & 0.000 & $48.317^{* * *}$ & 0.000 & $48.967^{* * *}$ & 0.000 & $46.958^{* * *}$ & 0.000 \\
\hline Number of Observations & 65 & & 65 & & 86 & & 86 & \\
\hline R-squared & 0.408 & & 0.351 & & & & & \\
\hline
\end{tabular}

${ }^{*} \mathrm{p}<0.1{ }^{* *} \mathrm{p}<0.05{ }^{* * *} \mathrm{p}<0.01$

Table 3 - POLS country panel estimations with the SDPL as poverty line for 13 ECHP countries. Models (3) and (4) make use of multiple imputation. Standard errors are clustered. Own calculations. 